\title{
Spot Market Competition with Stranded Costs in the Spanish Electricity Industry
}

\author{
José Antonio García Martín \\ Universitat Pompeu Fabra and CEMFI
}

Working Paper No. 0106

June 2001

I would like to express my sincere gratitude to my supervisor A. Jorge Padilla for his helpful suggestions and constant support. I have also benefited from the comments of David García Martín, Esteban Nicolini, Juan Pablo Nicolini, and seminar audiences at the 10th EEA Summer School on "Regulation of European Markets" in Toulouse, the 14th Annual Congress of the EEA held at Santiago, the 15th Jornadas de Economía Industrial in Madrid, the 24th Simposio de Análisis Económico in Barcelona, U. Pompeu Fabra, CEMFI, U. Nacional de Tucumán and U. Torcuato di Tella. All remaining errors are mine. (Email address: joseant@cemfi.es).

CEMFI, Casado del Alisal 5, 28014 Madrid, Spain.

www.cemfi.es 


\begin{abstract}
In this paper we have developed a model which analyzes price competition in the deregulated Spanish electricity market. This model is the first to take explicitly into account the mechanism designed in the recent Spanish Electricity Law for settling stranded costs payments. We show that stranded costs recovery and efficient competition are not necessarily incompatible. The settlement mechanism for stranded costs currently prevailing in Spain leads unambiguously to lower prices; it actually acts as a countervailing force to market power and high prices in these market. Whether equilibrium prices are higher or lower than marginal cost depends both on the distribution of total stranded cost payments among industry participants and on the exact rules used to define the entitlements.
\end{abstract}

Keywords: Oligopolistic models, regulation, electricity markets. JEL Classification: D4, L5, L9, K2. 


\section{Introduction}

Recent regulatory reform in Spain has led to a process of liberalization in the Spanish electric sector. The approval by the Spanish Parliament of the Law for the Electric Sector established the basis for a new competitive system. From January 1, 1998, wholesale electricity prices are set by the market rather than being subject to direct regulation by the government, as it had been the case prior to the enactment of this law. Yet, prior to complete liberalization, a transition period of ten years has been established to facilitate the conversion of incumbent firms towards the new competitive environment and to limit the impact of competition on the earnings of the electricity companies.

The establishment by the Electricity Law of a competitive framework in generation activities interrupted the remuneration process under which generating companies undertook their investments on infrastructures as well as their contractual obligations. On the basis of the existing regulatory setting, many assets were guaranteed a return which may not be recoverable following the introduction of a competitive market. The costs associated with these investments and contractual obligations that are not recoverable as the competitive system is implemented are known as stranded costs (costes de transición a la competencia-CTC-in the terminology of the Law). ${ }^{1} \quad$ The Electricity Law includes a series of transitory measures to compensate generation companies for these stranded costs.

Most of the public debate in Spain has been focused on the appropriate mag-

\footnotetext{
${ }^{1}$ At present, the issue of "stranded assets" becomes a central problem in the process of liberalization of all European Community electricity markets. On August 4, 1998, twelve European Community governments had already communicated to EC Energy Commission their purpose to compensate national generation companies for their stranded costs. Only Italy, Finland and Sweden did not do it. For more details see Cinco Dias, August 4, 1998.
} 
nitude for the stranded costs to be recovered by the Spanish electricity industry. ${ }^{2}$

However, not much attention has been paid to the potential distortions that the recovery of stranded costs can create in the recently created Spanish electricity market. A frequent claim made against measures purporting to ensure the recovery of stranded costs is that these provisions necessarily lead to inefficient competition, above marginal-cost pricing, inefficient despatching, erection of barriers to entry, etc. (See Kühn and Regibeau,1998, and Lasheras, 1998). In this paper I analyze whether price incentives are indeed distorted by stranded-cost recovery payments, or if in contrast, they end up promoting efficient competition in the Spanish electricity spot market.

I show that efficient competition and stranded-cost recovery are not necessarily incompatible. I find that price competition is fiercer in the current Spanish electricity market with stranded-cost payments than in an otherwise identical market without stranded costs. In other words, the settlement procedure for the recovery of stranded costs currently in place in Spain leads unequivocally to lower prices. Whether equilibrium prices are higher or lower than marginal cost, however depends both on the distribution of total stranded-cost payments among industry participants and on the exact rules used to define these entitlements. These rules are somewhat ambiguous in the current Law. This paper also establishes the conditions under which I should not expect cost shifting practices, i.e., generators bidding above or below marginal cost. The reason is essentially the same to that one developed by Kreps and Scheinkman (1983) in the analysis of equilibrium pricing behaviour in a capacity-constrained oligopoly market. ${ }^{3}$

\footnotetext{
${ }^{2}$ See El País, July 12, 1998 and El País, October 29, 1998.

${ }^{3}$ See von der Fehr and Harbord (1993) for a useful and more extensive discussion about the interpretation of this particular result in the context of electricity spot markets.
} 
The study of electricity spot markets has received much attention in recent years and a number of theoretical and empirical studies exists, von der Fehr and Harbord (1997a) (1997b), Green (1996), Wolfram (1998b) and Newbery (1998). Modelling competition in electricity spot markets has been analyzed under two main different approaches. The first is taken by Green and Newbery (1992) and Bolle (1992) when they adapt the supply function model, due to Klemperer and Meyer (1989). A second approach is taken by von der Fehr and Harbord (1993). The latter opt for an auction approach and model price in the England and Wales electricity pool as a first-price, sealed-bid, multiple-unit auction. ${ }^{4}$ These authors find a tendency towards above marginal-cost pricing and inefficient despatching. In my paper I also opt for the auction approach. Focusing upon the case of duopoly, I make an attempt at modelling spot market competition with stranded costs as a first-price, sealed-bid auction. Kahn (1994) and Joskow (1996) also deal with the stranded-cost issue. While Kahn (1994) discusses the need for the coexistence of competition and regulation in the electric power industry, Joskow (1996) provides simple mechanisms to implement stranded-cost recovery policies that promote efficient competition. Jullien and Kühn (1998) show how optimal regulation involving a menu of price caps and price floors could optimally finance stranded assets in a context of liberalization of entry when government transfers to firms are not permitted. My results confirm that the implementation of strandedcost recovery in a spot market does not necessarily create additional distortions in the competition, at least no more than those that already appear in a typical spot market without stranded costs [von der Fehr and Harbord (1993)]. Furthermore, I show that an optimal stranded-cost recovery policy can hunt the existing price

\footnotetext{
${ }^{4}$ See Wolak and Patrick (1997) and von der Fehr and Harbord (1997b) for an extensive discussion of the alternative approaches.
} 
distortions. More importantly, although I can find recent attempts to simulate firms' behaviour in the Spanish electricity pool, my model is the first to take explicitly into account the mechanism designed in the recent Spanish Electricity Law for settling stranded-cost payments. ${ }^{5}$

This paper is organized as follows. The Spanish institutional setting is described in Section 2. Section 3 presents the auction model of the Spanish electricity spot market and discusses the assumptions. Section 4 is devoted to analyze the model for the basic symmetric case. Section 5 extends the model to deal with the asymmetric case and an alternative regulatory rule. Finally, Section 6 concludes.

\section{The Spanish Electricity Industry}

In this section I describe the structure of the Spanish electricity industry, as well as the new market rules that organize and regulate the electricity spot market since January 1998. These rules were adapted with the objective of introducing competition in the Spanish electricity market. I will also describe the mechanism through which incumbents will recover their stranded costs.

\subsection{The Structure of the Spanish Industry}

Although there are over 1,000 companies involved in the Spanish Electricity Industry, production and distribution of electricity is concentrated in two main companies: the Endesa Group -a publicly owned company currently undergoing privatisation- and Iberdrola -a private company-.

\footnotetext{
${ }^{5}$ See Ocaña and Romero (1998) and Marín and García-Díaz (2000) for an extensive analysis of firms' behaviour in the Spanish pool. While the first paper uses the Cournot model to the Spanish pool, Marín and García-Díaz (2000) opts to generalize Von der Fehr and Harbord's (1993) multi-unit auction model for the case of a deterministic demand.
} 
The Endesa Group is Spain's largest electricity company. Total group installed capacity now represents $47 \%$ of the Spanish generating capacity (including that of autoproducers), and $41 \%$ of electricity distribution in Spain. It owns or controls $22 \mathrm{GW}$ of generating plant, $7 \mathrm{GW}$ within the parent company, and further $15 \mathrm{GW}$ through its main subsidiaries. These now include Fecsa (Endesa owns $75 \%$ of its outstanding shares), Sevillana (75.1\% Endesa), Enher (91.4\% Endesa), Unelco (99.7\% Endesa), Viesgo (87.6\% Endesa), Gesa (55.3\% Endesa), Saltos del Nansa (85\% Endesa) and ERZ (61.2\% Endesa). Endesa parent company's production is mainly based upon coal fired power stations (with 4.5GW of installed capacity, of which $2.4 \mathrm{GW}$ uses coal produced by Endesa's own mines). It also has direct interests in nuclear plants with total capacity 1.5GW.

Iberdrola is the second largest electricity company in Spain, with an installed capacity of over $16 \mathrm{GW}$, which represents a $28 \%$ of Spanish generating capacity. Iberdrola is Spain's largest owner of hydroelectric power stations, with capacity of 8.2GW, and output ranging from 9-20TWh. Nuclear power is its major source of production. Iberdrola has also $39 \%$ of the Spanish electricity distribution market.

In addition to these two major companies, there are two smaller firms, namely Unión Fenosa, with $10.8 \%$ of the generating capacity, and Hidro Cantábrico with 3.5\%. As well as these utilities, over 350 companies are involved in autoproduction, producing $11 \%$ of Spain's total electricity output. In 1998, the import net value of international exchanges with France and Portugal amounted to 4.590 GWh, accounting for $3 \%$ of total generation.

The electricity distribution market is mainly controlled by the aforementioned companies: Endesa, Iberdrola, Unión Fenosa, Fecsa, Sevillana and Hidro Cantábrico; $97 \%$ of electricity is distributed by these six companies. Iberdrola with 
approximately $39 \%$ of the distribution market, Unión Fenosa with more than $15 \%$ and Sevillana with further $13 \%$ are the three main distributors. Endesa parent company has no distribution assets.

Transmission is the responsibility of Red Eléctrica de España (REE). REE is the transmission system operator and runs the transport network. REE is owned by the major electricity utilities in Spain. It owns and operates $60 \%$ of the transmission lines operating at voltages above $220 \mathrm{KV}$. The high voltage lines outside REE's control are owned by Iberdrola and Sevillana.

\section{$2.2 \quad$ Market Rules}

The approval by the Spanish Parliament of the Law for the Electric Sector (Law 54/1997) on November 1997 established the foundations for the new competitive system in the Spanish Electric Sector. This law established a new electricity market for the trading of electricity between generators and purchasers (generators, distributors, commercialisers and qualified customers) in Spain. From January 1, 1998, wholesale electricity prices are set by a market rather than being subject to direct regulation by the government, as it had been the case prior to the enactment of this law. The main feature of the new market structure is that despatch is to be based on a competitive bidding process in which the system price is settled by the interplay of supply and demand.

The law establishes a pool system with two responsible institutions for coordinating and running the transmission grid: the System Operator and the Market Operator. The aim of the System Operator is to coordinate the despatch of electricity, whereas the Market Operator manages the economic features of the system (for instance, the calculation and processing of payments across firms, the match- 
ing of supply and demand bids, and the calculation of the price of electricity). The Electricity Law also creates La Comisión Nacional del Sistema Eléctrico (CNSE). The CNSE is the regulatory body for the electric system, which supervises the proper functioning of the whole sector.

Each participant in the pool market sends to the Market Operator its offers to supply/purchase. These must include for each hour of the day (a) the amount of capacity of each type it wishes to supply/purchase and (b) the minimum/maximum price at which it is willing to sell/buy. Generators must also inform of any special technical or economic limitations applying to their power plants. $^{6}$

Generation sets are then ranked according to their offer prices (i.e., the supply function is constructed) in increasing order of cost to create the "merit order", which thus comprises the generation units with lower costs among all those offered to the market. This is used to despatch the system at the least possible cost. Likewise, a demand function is constructed from the purchase bids. The spot price of electricity in the pool, the so-called system marginal price (SMP), is determined by the intersection of demand and supply: the SMP is therefore the bid price of the marginal operating unit, i.e., the most expensive plant that is running on the system.

The SMP is the major component of the overall price paid for each despatched generating unit, which comprises:

- the system marginal price (SMP), increased to take into account transmission losses;

\footnotetext{
${ }^{6}$ Until April 1998, the offers to purchase power in the daily market could only specify the quantity demanded, but not its price.
} 
- the capacity guarantee (GdP-Garantía de Potencia), which compensates generators for providing capacity or "security of supply" to the system. The remuneration for capacity guarantee is intended to be an economic signal for investment in new generation capacity. In 1998 the capacity price added $1.3 \mathrm{Pta} / \mathrm{kWh}$ to the SMP; ${ }^{7}$

- the cost of ancillary services, which are services purchased by the grid company to ensure the stability of the system. These include black start, reactive power, and reserve services;

- a price incentive for the cost of small-scale renewable power; and

- the cost of the Market Operator and the CSEN;

\subsection{Stranded-Cost Recovery}

Under the old regulatory system, which was overruled by the Law of 1997, generating companies were guaranteed a return based on a value-estimate of their assets, known as "standard value", and their costs, known as "standard costs". This system implied an average generation wholesale price of $9 \mathrm{Pta} / \mathrm{kWh}$. This price was regarded by most as excessively high. An estimate of the competitive price was fixed around $6 \mathrm{Pta} / \mathrm{kWh}$. The sudden introduction of competition in generation brought by the Electricity Law interrupted the remuneration process under which generating companies undertook their investments on infrastructures, whose aim was to guarantee the supply of electricity and whose costs cannot be recovered at market prices. Something similar occurred with those contractual

\footnotetext{
${ }^{7}$ The recent approval by the Spanish Parliament of the modification of the Law for the Electric Sector (Law 54/1997) on December 1998 established a reduction of the remuneration for capacity guarantee from $1.3 \mathrm{Pta} / \mathrm{kWh}$ to $0.3 \mathrm{Pta} / \mathrm{kWh}$.
} 
obligations acquired in the past at prices different from current market prices, or with those costs whose recovery was differed (costes diferidos).

Those costs, incurred by the generating companies under the old regulatory system, which cannot be recovered due to the introduction of a competitive market are known as stranded costs. The Electricity Law includes a series of provisions to compensate the generation companies for these stranded costs.

The maximum amount of stranded costs awarded to companies was set at Ptas 1,988,561 millions. It was determined as follows. First, the net present value of the difference in revenues that generating companies could obtain under the old and new systems was estimated under the assumption that the competitive market price would be $6 \mathrm{Pta} / \mathrm{kWh}$. Second, to this difference, a $32.5 \%$ reduction was applied to reflect improvements in productive efficiency. Finally, to this result, an amount of Ptas 295,276 millions was added to subsidise national coal. The final result implies a total amount of stranded costs of Ptas 1,988,561 millions. The total value of these payments is to be paid in annuities to the current owners of the generation sets in a 10-year period ending in 2007, and it is recovered from a charge per kWh made to all final customers. Total stranded costs minus the subsidy to national coal, an amount of Ptas 1,693,285 millions, are divided among generation firms in the industry as follows: ENDESA (31,03\%), Iberdrola S.A. (27,1\%), Unión Eléctrica Fenosa, S.A. (12,9\%), Fuerzas Eléctricas de Cataluña, S.A. (10\%), Hidroeléctrica del Cantábrico, S.A. (5,7\%), Compañía Sevillana de Electricidad, S.A. (5,40\%), Elcogás, S.A. (3,1\%), E. N. Hidroeléctrica del Rigagorzana, S.A. (1,68\%), Electra de Viesgo, S.A. (1,66\%), Hidroeléctrica de Cataluña, S.A. (0,77\%), and Eléctricas Reunidas de Zaragoza, S.A. $(0,66 \%){ }^{8}$

\footnotetext{
${ }^{8}$ For more details, see Royal Decree 2019/1997, December 26, 1997, (Real Decreto por el que se organiza y regula el procedimiento de liquidación de los costes de transporte, distribución y
} 
The Law does not give generators the right to claim this maximum amount, which remains as an upper bound for actual payments for stranded costs. Each year a reference volume of stranded-cost payments is established. Annual strandedcost payments are shared among firms in the industry according to the previously stated percentages. For instance, the reference amount for 1998 was estimated to be Ptas 206,878 millions. This reference amount implicitly defines a reference average pool price for each year, i.e., if the actual average pool price coincides with this reference price, stranded-cost payments will be set at this reference value. Actual payments may exceed or fall below this reference amount, depending on the average pool price for that year. If those payments exceed the reference threshold, which occurs when the average pool price is below the reference price, then the excess will be applied to diminish the payments made in future years. This, however, would not reduce the maximum entitlement for the industry. It just implies that the stranded costs will be recovered earlier. Actual payments cannot exceed the maximum amount of Ptas 1,988,561 millions as defined by law. This implicitly defines a floor price below which actual stranded-cost payments will not increase any further.

If the average pool price exceeds the reference price, then actual payments for stranded costs are less than the reference payments. Furthermore, if the average pool prices is larger than $6 \mathrm{Pta} / \mathrm{kWh}$, the maximum entitlement is reduced by the difference between actual industry revenues and the amount that the generating companies would have earned with a pool price of $6 \mathrm{Pta} / \mathrm{kWh}$.

The procedure through which the annual reference amount of stranded costs is defined remains unclear. Since the annual reference amount of stranded costs comercialización a tarifa, de los costes permanentes del sistema y de los costes de diversificación y seguridad de abastecimiento). 
is established by Law before the commencement of each year, it is expected that it was computed taken into account the expected demand for the year, given the remaining amount of stranded-cost compensations yet to be made. Likewise, the mechanism that will be used to calculate the actual stranded costs that each generating firm will receive at the end of the year remains confusable in some points. ${ }^{9} \quad$ This is important when actual demand differs from expected demand or actual average pool price differs from the reference price. I know that an average pool price below the reference price gives the generating companies an actual amount of stranded costs that is higher than the reference amount, but how much more? Is the increment proportional to the actual demand or to the expected demand? Let me suppose that the actual average pool price is below the reference price, but the real demand has been extremely high, do the generating companies still receive stranded-cost payments higher than those established as reference? The Law does not sufficiently clarify whether stranded-cost recovery payments are computed according to the actual (ex post) demand or, by the contrary, the stranded-cost recovery rule is based on the forecasted demand at the beginning of each transition period, as it is the case for the reference stranded costs. Section 4 and subsection 5.2 analyze these two alternative recovery rules and demonstrate that these are non trivial questions, because the outcomes obtained under the recently established Spanish pool market can dramatically change, depending on their answers.

\footnotetext{
${ }^{9}$ The Law remains silent on this point and personal communications with the regulators (CNSE) suggest that this issue is not yet settled.
} 


\section{The Model}

I consider a duopolistic market for electricity with two independent generators, both of them with identical constant marginal costs, without loss of generality equal to zero at production levels below capacity. ${ }^{10}$ Each firm has one generating unit with capacity, $k_{i}$, normalized to 1 , so that total industry capacity, $K=$ $\sum_{i=1}^{2} k_{i}$, is equal to 2 . Power demand, $d$, is modeled as a discrete random variable independent of price, distributed on $\{1,2\}$, with probabilities $\pi=\operatorname{Pr}(d=1)$ and $(1-\pi)=\operatorname{Pr}(d=2)$, respectively.

In the first stage of the model, before the actual opening of the market, risk neutral firms, simultaneously and non-cooperatively submit offer prices, $p_{i} \leq \bar{p}$, $i=1,2$, at which they are willing to supply power. ${ }^{11}$ Prices are constrained to be below a threshold $0<\bar{p}<\infty$. Von der Fehr and Harbord (1993) provide various justifications for this upper bound on offer prices: "[This bound must be included in the analysis] since otherwise, in cases when there is a positive probability that all sets will be called into operation, expected payoffs could be made infinitely large. Natural interpretations of $\bar{p}$ are that it is a (regulated) maximum price, either officially, or as perceived by the generators (i.e., firms believe that the regulation authorities will introduce price regulation if the price raises above $\bar{p}$ ). An alternative interpretation is that $\bar{p}$ is a reservation price, below which demand is completely inelastic". These intuitions also apply to my model.

On the basis of these bids, an auctioneer draws up a ranking of sets according

\footnotetext{
${ }^{10}$ Our discussion is centred on the duopoly case for two reasons, (a) this is the relevant case for the Spanish electricity industry, where the two main generating companies Endesa and Iberdrola produce $80 \%$ of total generation; and (b) explicit formulae are difficult to obtain in the more general oligopoly case, specially when stranded costs are introduced in the model.

${ }^{11}$ The timing of the game purposes to reflect the actual functioning of the Spanish electricity market, whose rules are described in detail in section 2 .
} 
to their offer prices (i.e., the market supply curve is constructed) in increasing order of cost to create the "merit order". This is used to despatch the system at least cost. In the final stage of the game, when the market opens, demand is randomly realized. Contingent on this, the auctioneer, by calling suppliers into operation, equates demand and supply. When the bid of generator $i, p_{i}$, is lower than the bid of generator $j, p_{j}$, then firm $i$ will be ranked in the first position and it will be the marginal operating unit if demand equals 1 . Instead, when demand is 2 , firm $j$ will be the marginal operating unit. In the event that there is a tie at $p$, player $i$ is ranked below $j$ with probability $1 / 2$ and gets a payoff of $p$ whenever demand is equal to 1 or 2 , and with probability $1 / 2$ is ranked above $j$ and receives $p$ only when demand is 2 . Operating units, i.e., units actually supplying output, are paid according to the system marginal price, which is defined to be equal to the offer price of the marginal operating unit.

The system marginal price determines not only the payoffs that generators obtain via generation, but also the revenues that firms obtain via stranded-cost recovery (SCR, hereafter). Let $G_{i}\left(p_{i}\right)$ denote the firm $i$ 's expected generation revenues, and $S_{i}\left(p_{i}\right)$ be the firm $i$ 's expected SCR revenues, when firm $i$ and firm $j$ bid at prices $p_{i}$ and $p_{j}$ respectively. Then, firm $i$ 's expected profits, $\Pi_{i}\left(p_{i}\right)$, are given by

$$
\begin{aligned}
& \Pi_{i}\left(p_{i}\right)=\underbrace{G_{i}\left(p_{i}\right)}+\underbrace{S_{i}\left(p_{i}\right) .} \\
& \text { Generation } \quad S C R \\
& \text { Revenues Revenues }
\end{aligned}
$$

Firm $i$ 's generation payoffs are determined by the electricity supplied to the spot market by firm $i$ and the pool price, which is settled by the marginal operating unit. Ex ante, prior to the opening of the market, the expected generation payoffs 
for each firm are given by the equation below,

$$
G_{i}\left(p_{i}\right)=\left\{\begin{array}{lll}
(1-\pi) p_{i} & \text { if } & p_{i}>p_{j}, \\
\frac{1}{2} \pi p_{i}+(1-\pi) p_{i} & \text { if } & p_{i}=p_{j}, \\
\pi p_{i}+(1-\pi) p_{j} & \text { if } & p_{i}<p_{j}, \\
i, j=1,2, i \neq j \text { and } & p_{i} \leq \bar{p} .
\end{array}\right.
$$

Current expected generation profits can be rewritten as,

$$
\begin{aligned}
G_{i}\left(p_{i}\right)= & {\left[\pi\left(1-F_{j}\left(p_{i}\right)\right)+(1-\pi) F_{j}\left(p_{i}\right)\right] p_{i} } \\
& +(1-\pi) \int_{p_{i}}^{\bar{p}} \rho f_{j}(\rho) d \rho, \quad i, j=1,2, i \neq j,
\end{aligned}
$$

where

$$
F_{j}\left(p_{i}\right) \equiv \operatorname{Pr}\left(p_{j} \leq p_{i}\right)
$$

is the cumulative probability that firm $j$ charges a price smaller than $p_{i}$. Let $\operatorname{supp} F_{j}$ be the support of $F_{j}$ with $\underline{p}_{j}, \bar{p}_{j}$, being its lower and upper bounds, and $f_{j} \equiv d F_{j} / d p$ be the corresponding density function.

The first term in (3) reflects firm $i$ 's expected generation revenues in the event that it is the marginal supplier, which occurs with probability $\left(1-F_{j}\left(p_{i}\right)\right)$ when $d=1$, and with probability $F_{j}\left(p_{i}\right)$ when $d=2$. The second part of (3) represents firm $i$ 's generation payoffs when bidder $j$ sets the price, but demand is 2 so that the firm $i$ 's unit is dispatched.

Unlike its generation revenues, firm i's SCR revenues do not depend on its actual supply of electricity to the spot market. Instead, they depend on the 
expected demand for electricity that has to be served by the whole generation industry. ${ }^{12}$ In fact, a firm obtains SCR payoffs even when it is not producing.

Let $S(p)$ be a continuous and monotonically decreasing function which denotes the total SCR payoffs shared by the industry participants when the system marginal price is $p$, and $\bar{S}$ be the maximum amount of SCR payoffs to be distributed among generators, i.e., $0 \leq S(p) \leq \bar{S}$. Furthermore, I assume that $S(0)<\bar{S}, S(\bar{p})>0$ and $S(p) \equiv \bar{S}, \forall p \leq p_{r}$. Consequently, given that $S(0)<\bar{S}$ and $S^{\prime}(p) \leq 0$, I have that $p_{r}$, the price that maximizes SCR payoffs, is strictly less than 0 , the common marginal cost of generation.

I denote by $S$ the reference SCR payment set by the regulator for the industry as a whole and designate as $E[$.$] the expectation operator. { }^{13}$ The reference SCR payment is calculated as a function of the expected demand, $E[d]$, and the reference price, $p^{*} \in[0, \bar{p}]$, so that,

$$
S(p)=S-\left(p-p^{*}\right) E[d]
$$

where $p$ is the prevailing system marginal price, and $E[d]=2-\pi$. It is immediate that $S\left(p^{*}\right)=S$.

Total SCR payoffs are thus a function of the difference between the pool price, $p$, and the reference price, $p^{*}$. Therefore, a reduction in the pool price, which leads to a fall in generation revenues, is compensated with an increase in the revenues accruing from stranded-cost recovery. A pool price, $p$, higher than $p^{*}$ will generate SCR payoffs for the industry lower than the reference SCR payoffs, $S$, and vice

\footnotetext{
${ }^{12}$ See Royal Decree 2019/1997, December 26, 1997 (Real Decreto por el que se organiza y regula el procedimiento de liquidación de los costes de transporte, distribución y comercialización a tarifa, de los costes permanentes del sistema y de los costes de diversificación y seguridad de abastecimiento).

${ }^{13}$ Since we have normalized each firm's capacity to $1, S$ denotes the SCR reference payment per unit capacity.
} 
versa.

Total SCR payoffs, $S(p)$, are shared among generators as established by law. Let $\theta_{i}$ denote the firm $i$ 's SCR share, so that $\theta_{i} \in(0,1), i=1,2$, and $\sum_{i=1}^{2} \theta_{i}=1 .{ }^{14}$ This means that, ex post, once the market has closed and the pool price, $p$, has been announced by the auctioneer, the SCR payoffs corresponding to firm $i$, are given by,

$$
S_{i}(p)=S(p) \theta_{i}, \quad i=1,2 .
$$

Ex ante, prior to the actual opening of the market, when both independent firms simultaneously submit their offer prices, expected SCR payoffs for each firm are:

$$
S_{i}\left(p_{i}\right)= \begin{cases}\left\{S-\left[\left(\pi p_{j}+(1-\pi) p_{i}\right)-p^{*}\right] E[d]\right\} \theta_{i} & \text { if } p_{i}>p_{j}, \\ \left\{S-\left[p_{i}-p^{*}\right] E[d]\right\} \theta_{i} & \text { if } p_{i}=p_{j}, \\ \left\{S-\left[\left(\pi p_{i}+(1-\pi) p_{j}\right)-p^{*}\right] E[d]\right\} \theta_{i} & \text { if } p_{i}<p_{j}, \\ i, j=1,2, i \neq j \text { and } p_{i} \leq \bar{p} . & \end{cases}
$$

Note that both firms share the SCR payoffs equally when their SCR shares coincide, independently of their offer prices. Current expected SCR profits can be rewritten as,

$$
S_{i}\left(p_{i}\right)=\left\{S-\left(E\left[p \mid p_{i}\right]-p^{*}\right) E[d]\right\} \theta_{i},
$$

where $E[d]=2-\pi$ and $E\left[p \mid p_{i}\right]$ is given by equation (9) below, which represents the firm $i$ 's expected system marginal price given that firm $i$ bids at $p_{i}$,

$$
E\left[p \mid p_{i}\right]=\left[\pi\left(1-F_{j}\left(p_{i}\right)\right)+(1-\pi) F_{j}\left(p_{i}\right)\right] p_{i}
$$

\footnotetext{
${ }^{14}$ Recall from section 2.3 that the share of stranded costs assigned to Endesa is 31,03\%, whereas $27,10 \%$ corresponds to Iberdrola.
} 


$$
+\pi \int_{\underline{p}}^{p_{i}} \rho f_{j}(\rho) d \rho+(1-\pi) \int_{p_{i}}^{\bar{p}} \rho f_{j}(\rho) d \rho .
$$

From equations (3) and (8), and rearranging terms, I have that the firm $i$ 's expected profits, can be written as

$$
\Pi_{i}\left(p_{i}\right)=\eta\left(\theta_{i}\right) A\left(p_{i}\right)+B\left(p_{i}\right) \theta_{i},
$$

where

$$
\begin{gathered}
A\left(p_{i}\right) \equiv(1-\pi) \int_{p_{i}}^{\bar{p}} \rho f_{j}(\rho) d \rho+\left(\pi+F_{j}\left(p_{i}\right)(1-2 \pi)\right) p_{i}, \\
B\left(p_{i}\right) \equiv S-(2-\pi)\left(\pi \int_{\underline{p}}^{p_{i}} \rho f_{j}(\rho) d \rho-p^{*}\right),
\end{gathered}
$$

and

$$
\eta\left(\theta_{i}\right) \equiv 1-(2-\pi) \theta_{i}
$$

Consequently, the firm $i$ 's expected marginal profits are equal to:

$$
\Pi_{i}^{\prime}\left(p_{i}\right)=\eta\left(\theta_{i}\right)\left[\pi+F_{j}\left(p_{i}\right)(1-2 \pi)\right]-\pi p_{i} f_{j}\left(p_{i}\right)
$$

The intuition behind equation (14) is as follows. Firm $i$ 's profits are only affected by an increase in $p_{i}$ in two circumstances: (a) when firm $i$ determines the system marginal price, and (b) when an increase in $p_{i}$ forces firm $i$ out of the merit order. Otherwise, increasing $p_{i}$ has no (first-order) impact on profits. Firm $i$ is the marginal operating unit with probability $\left[\pi+F_{j}\left(p_{i}\right)(1-2 \pi)\right]$, and the net marginal benefit for firm $i$ of raising $p_{i}$ in this case is $\eta\left(\theta_{i}\right)$, as given by equation (13). This last term, in turn, comprises two effects. Provided that firm $i$ is the marginal operating unit, an increase of $p_{i}$ raises generation revenues in the same proportion, since capacity is 1 , but lowers SCR revenues. The marginal loss in SCR revenues is equal to $E[d] \theta_{i}=(2-\pi) \theta_{i}$. To complete the explanation of 
equation (14), note that an increase in $p_{i}$ will move firm $i$ out of the merit order with probability $\pi f_{j}\left(p_{i}\right)$, which will in turn entails a reduction of $p_{i}$ in generation revenues. Recall that SCR payoffs are not linked to actual production.

The net marginal benefit, $\eta\left(\theta_{i}\right)$, plays a crucial role in the determination of the generators' equilibrium strategies, since as it is clear from (14), pricing incentives depend on the sign and magnitude of $\eta\left(\theta_{i}\right)$. For instance, if the firm $i$ 's SCR share, $\theta_{i}$, and the probability of low demand, $\pi$, are such that $\eta\left(\theta_{i}\right)<0$, then the firm $i$ 's expected marginal profits are negative, and so, firm $i$ will always bid below marginal cost at $p_{r}$, the price which maximizes the SCR payoffs. Otherwise, firms have incentives to raise prices above marginal cost, as I proceed to show in the next section.

\section{The Analysis: The Basic Symmetric Case}

In this section, I find and characterize the Nash equilibria of the model presented above. The existence, multiplicity and type of equilibria in my model depend on the support of the demand distribution, as in von der Fehr and Harbord (1993), as well as on the distribution of stranded-cost revenues.

Concerning demand, I shall consider three scenarios: 'High-Demand Periods' in which demand is equal to 2 with probability 1, so that both firms will necessarily supply the market, 'Low-Demand Periods' in which demand is equal to 1 with probability 1, and so, only one firm supplies the market, and 'Fluctuating-Demand Periods' in which demand may be high and low with probabilities $1-\pi$ and $\pi$, respectively.

In this section, I assume that $\theta_{1}=\theta_{2}=\frac{1}{2}$, and consequently stranded-cost recovery payoffs are equally shared among generators. Note that this assumption 
implies that $\eta\left(\theta_{1}\right)=\eta\left(\theta_{2}\right)=\frac{\pi}{2} \geq 0$, so that the marginal operator has the incentive to marginally increase its offer price.

The analysis is considerably simplified when $\pi=0$ or $\pi=1$. In both scenarios, pure strategy equilibria are found. In contrast, when $0<\pi<1$, I find that there does not exist an equilibrium in pure strategies, but a unique symmetric equilibrium in mixed strategies is obtained with firms bidding above marginal cost.

\subsection{High-Demand Periods}

I turn to the case in which demand is equal to 2 with probability one, so that both firms are called into operation with probability one and they supply to the market at their full capacities. Pure strategy equilibria are found which are characterized in the proposition below.

Proposition 1 If $\pi=0$, any offer-price pair $\left(p_{1}, p_{2}\right)$ satisfying that $\max \left\{p_{1}, p_{2}\right\}$ $\in\left[p_{r}, \bar{p}\right]$ constitutes a pure-strategy equilibrium for this game.

Proof. Since $S(p) \equiv \bar{S}, \forall p \leq p_{r}, \pi=0$ and $\theta_{i}=\frac{1}{2}$, I have that the firm $i$ 's net marginal benefit of raising $p_{i}$, when firm $i$ is the marginal operating unit, is given by

$$
\eta\left(\frac{1}{2}\right)=\left\{\begin{array}{lll}
0 & \text { if } \quad p_{i} \in\left[p_{r}, \bar{p}\right] \\
1 & \text { if } \quad p_{i}<p_{r}
\end{array}\right.
$$


Substituting this into equation (14) I get that

$$
\Pi_{i}^{\prime}\left(p_{i}\right)= \begin{cases}0 & \text { if } p_{i} \in\left[p_{r}, \bar{p}\right] \\ F_{j}\left(p_{i}\right) & \text { if } p_{i}<p_{r} .\end{cases}
$$

Suppose that in equilibrium $p_{1}, p_{2} \in\left[p_{r}, \bar{p}\right]$. From the previous equation, it is clear that no firm has ever an incentive to deviate from its equilibrium bid, since the marginal profit of raising or lowering its offer price is equal to zero. Therefore, any offer-price pair $\left(p_{1}, p_{2}\right)$ satisfying that $p_{i} \in\left[p_{r}, \bar{p}\right]$, for all $i=1,2$, constitutes a pure-strategy equilibrium of this game. Any offer-price pair $\left(p_{i}, p_{j}\right)$ such that $p_{i} \in\left[p_{r}, \bar{p}\right]$ and $p_{j}<p_{r}$ also constitutes a pure-strategy equilibrium for the game. As before, from equation (16), I have that firm $i$ never has an incentive to deviate from its bid, $p_{i}$. Firm $j$ has not an incentive to deviate either: $\Pi_{j}^{\prime}\left(p_{j}\right)=F_{i}\left(p_{j}\right)=$ 0 since $p_{j}<p_{r} \leq p_{i}$. Finally, I show that any offer-price pair $\left(p_{1}, p_{2}\right)$ satisfying that $p_{i}<p_{r}$, for all $i=1,2$, cannot be a pure-strategy equilibrium. Suppose that $p_{i}<p_{r}$, for all $i$, and take $p_{j} \leq p_{i}$, w.l.o.g. Then, from equation (16), $\Pi_{i}^{\prime}\left(p_{i}\right)=F_{j}\left(p_{i}\right)>0$, so that firm $i$ 's profits are strictly increasing in its own bid. Consequently, firm $i$ will raise its price and $\left(p_{i}, p_{j}\right), p_{j} \leq p_{i}<p_{r}$, cannot be an equilibrium Q.E.D.

For $\pi=0$ and $\eta\left(\frac{1}{2}\right)=0$ the firm $i$ 's profits function is given by

$$
\Pi_{i}\left(p_{i}\right)=\left(\frac{S}{2}+p^{*}\right), \quad \text { for all } p_{i} \in\left[p_{r}, \bar{p}\right], i=1,2,
$$

i.e., firm $i$ 's profits are independent of its own bid, and its marginal incentive to raise its offer-price is equal to zero for any offer-price $p_{i}$ in the support $\left[p_{r}, \bar{p}\right]$, irrespective of $p_{j}{ }^{15}$ The intuition behind this is straightforward. Given

\footnotetext{
${ }^{15}$ If we allow firms to have asymmetric generating capacity shares, i.e. $k_{i}>k_{j}$, the net marginal benefit for firm $i$ of raising $p_{i}$ when it is the marginal operating unit is $\eta\left(\theta_{i}\right)=$
} 
that demand is 2 with probability one, an increase in $p_{i}$ does never force firm $i$ out of the merit order (i.e., $\pi p_{i} f_{j}\left(p_{i}\right)=0$ ), and so, both firms always supply to the market at their full capacities. In addition, provided that firm $i$ sets the system marginal price, what it earns via generation when its offer price raises is exactly offset by with what it losses in stranded costs, so that $\eta\left(\frac{1}{2}\right)=0$ when $p_{i} \in\left[p_{r}, \bar{p}\right]$. Hence, I have that $\Pi_{i}^{\prime}\left(p_{i}\right)=0$ in this price interval, and consequently any offer-price pair $\left(p_{1}, p_{2}\right)$ satisfying that both offer-prices belong to the interval $\left[p_{r}, \bar{p}\right]$ constitutes a pure-strategy equilibrium of the game.

Firm $i$ bidding at any price $p_{i}$ in the interval $\left[p_{r}, \bar{p}\right]$, while firm $j$ bids at $p_{j}<p_{r}$ also constitutes a pure-strategy equilibrium. As just argued, the highbidding firm $i$ has no incentive to deviate as it is indifferent among all prices in $\left[p_{r}, \bar{p}\right]$, irrespective of what firm $j$ does. But neither it does the low-bidding firm $j$ given that its profits are independent of its own bid: its bid does not constitute the system marginal price and it produces at full capacity since demand is 2 . Finally, note that both firms bidding at prices below $p_{r}$ cannot constitute an equilibrium. From section 3, I know that stranded-cost recovery payments are always constant at the maximum level $\bar{S}$ for any price below $p_{r}$. As a result, a marginal increase in the system marginal price only affects firms' profits through generation payments. Since demand is 2 with probability one, so that no firm can be out of the merit order, this implies that both firms have an incentive to raise their offer prices in order to increase their generation revenues at no cost in terms of stranded payments. Summing up, from Proposition 1, when demand is high the system marginal price can be at any price $p \in\left[p_{r}, \bar{p}\right]$.

$\overline{k_{i}-(2-\pi) \theta_{i}, \forall p_{i} \in\left[p_{r}, \bar{p}\right] . \text { It implies }}$ that in the general case proposition 1 holds if and only if $k_{i}=2 \theta_{i}$. 


\subsection{Low-Demand Periods}

In this sub-section I assume that demand is equal to 1 with probability one, i.e., $\pi=1$, so that only one firm supplies the whole demand.

Proposition 2 If $\pi=1$, there exists a unique pure-strategy equilibrium, in which the system marginal price equals marginal cost and only one generator supplies the market.

Proof. Suppose $0<p_{i}<p_{j}$, then firm $j$ has an incentive to undercut its rival's bid in an arbitrarily small amount $\varepsilon>0$. If $j$ plays $p_{i}-\varepsilon$ it gets a strictly higher payoff, since its stranded-cost receipts are constant but its generation revenues raise by $p_{i}>0$. Suppose now that $0<p_{i}=p_{j}$. This cannot be an equilibrium either, since again any firm can increase its profits by $p_{i} / 2$ when undercutting its rival. Suppose $p_{i}<p_{j} \leq 0$. Since $\pi=1$,

$$
0<\eta\left(\frac{1}{2}\right)=\left\{\begin{array}{lll}
\frac{1}{2} & \text { if } \quad p_{i} \in\left[p_{r}, \bar{p}\right) \\
1 & \text { if } \quad p_{i}<p_{r} .
\end{array}\right.
$$

Then, from equation (14), $\Pi_{i}^{\prime}\left(p_{i}\right)>0$ and hence, firm $i$ will raise its price so that $p_{i}<p_{j}<0$ cannot be an equilibrium. Likewise, $p_{i}=p_{j}<0$ cannot be an equilibrium either. Firm $i$ 's expected profits are equal to

$$
\Pi_{i}\left(p_{i}\right)= \begin{cases}\frac{1}{2}\left(S+p^{*}\right) & \text { if } \quad p_{i} \in\left(p_{r}, 0\right) \\ \frac{1}{2}\left(p_{i}+\bar{S}\right) & \text { if } \quad p_{i} \leq p_{r}\end{cases}
$$


If firm $i$ raises its price by $\varepsilon>0$, then its profits become

$$
\Pi_{i}\left(p_{i}+\varepsilon\right)= \begin{cases}\frac{1}{2}\left(S-p_{i}+p^{*}\right) & \text { if } p_{i} \in\left(p_{r}, 0\right) \\ \frac{1}{2} \bar{S} & \text { if } p_{i} \leq p_{r} .\end{cases}
$$

So that $\Pi_{i}\left(p_{i}+\varepsilon\right)>\Pi_{i}\left(p_{i}\right)$, which implies that $p_{i}$ cannot be part of an pure equilibrium strategy. Finally, I must check that $p_{i}=p_{j}=0$ is a Nash equilibrium. It is easy to check that no firm has an incentive to deviate, since, for all $i$ and $p_{j}=0, \Pi_{i}\left(p_{i}\right)$ is continuously increasing up to 0 and for all $p_{i} \in[0, \bar{p}]$ remains constant at its maximum value of $\Pi_{i}(0)=\frac{1}{2}\left(S+p^{*}\right)$. In conclusion, there exists an unique pure equilibrium in which firm $i$ and firm $j$ bid at marginal cost, and only one of them supplies the whole demand. Q.E.D.

Proposition 2 is an intuitive result and the argument used to prove it is equivalent to that of the typical Bertrand model. ${ }^{16}$ Since, with probability 1 demand can be covered by one generator only, the system marginal price is always set by the low bidding firm. Any offer-price, $p_{i}$, above marginal cost cannot be part of an equilibrium, since it will always be optimal for firm $j$ to undercut $p_{i}$ : firm $j$ obtains strictly larger generation revenues while its stranded-cost payoffs remain unchanged. Offer-prices below marginal cost cannot be part of an equilibrium either. Suppose firm $i$ bids at an offer-price below marginal cost and has a positive probability of being the marginal operating unit (i.e., $p_{i} \leq p_{j}<0$ ). Then, firm $i$ is receiving losses from generation in expected terms. By raising $p_{i}$, firm $i$ cuts its generation losses. It may also reduce its income from stranded-cost repayments.

\footnotetext{
${ }^{16}$ If we allow firms to have different marginal cost, i.e. $c_{j}>c_{i}$, there is no pure strategy equilibrium for our game. In order to avoid this non-existence problem, we must impose the tie-breaking rule that firm $i$ is called into operation with probability 1 whenever the firm's offer prices tie at $c_{j}$. This alternative tie-breaking rule has no bearing on our results when marginal costs are identical.
} 
But this last effect can be shown to be less important. Thus, any pure-strategy equilibrium must have both generators offering prices at marginal cost. Deviations which imply lower prices entails losses in generation larger than compensations in SCR payments, so that the net effect on profits is strictly negative, and deviations to higher prices involve no extra revenues.

\subsection{Fluctuating-Demand Periods}

I am dealing now with the case in which $0<\pi<1$, so that there is a positive probability of either firm becoming the marginal operating unit, independently of their bids. I find that there is no pure-strategy equilibrium in this case, but there exists a unique mixed-strategy equilibrium. Furthermore, I find that the lowest price in the support of the players' strategies is strictly greater than the common marginal cost, and is an increasing function of the highest possible price, $\bar{p}$.

Proposition 3 If $0<\pi<1$, then there does not exist an equilibrium in pure strategies for this game.

Proof. Suppose $\left(p_{i}, p_{j}\right)$ constitutes a pure-strategy equilibrium and $p_{i}<p_{j}$. Since $0<\pi<1$ then I have that

$$
0<\eta\left(\frac{1}{2}\right)= \begin{cases}\frac{\pi}{2} & \text { if } \quad p_{i} \in\left[p_{r}, \bar{p}\right) \\ 1 & \text { if } \quad p_{i}<p_{r} .\end{cases}
$$

Hence, from equation (14) I have that

$$
0<\Pi_{i}^{\prime}\left(p_{i}\right)=\left\{\begin{array}{lll}
\frac{\pi^{2}}{2} & \text { if } \quad p_{i} \in\left[p_{r}, \bar{p}\right) \\
\pi & \text { if } \quad p_{i}<p_{r},
\end{array}\right.
$$


so firm $i$ has an incentive to raise its offer price $p_{i}$. Therefore, any offer-price pair $\left(p_{i}, p_{j}\right)$ with $p_{i}<p_{j}$ cannot constitute a pure equilibrium. Suppose now that the offer-price pair $\left(p_{i}, p_{j}\right)$, where $p_{i}=p_{j}>0$, is a pure-strategy equilibrium. If firm $i$ reduces its price by $\varepsilon>0$, then it is easy to check that its expected profits raise by $\frac{1}{2} \pi(p-\pi \varepsilon)>0$ for $\varepsilon$ small enough, which implies that $p_{i}=p_{j}>0$ cannot be a pure-strategy equilibrium. Likewise, $p_{i}=p_{j} \leq 0$ cannot be an equilibrium either, since $\Pi_{i}^{\prime}\left(p_{i}\right)>0$, for all $i$ when $p_{i} \leq 0$, irrespective of $p_{j}$. Q.E.D.

The intuition behind this result is the following. Suppose that a pure-strategy equilibrium exists and that firm $i$ is the lowest bidder. In this case, firm $i$ has an incentive to raise its offer price towards the firm $j$ 's bid. This raises its profits by $\eta\left(\frac{1}{2}\right)>0$ when demand is 1 and leaves them unaffected, otherwise. This implies that any offer-price pair $\left(p_{i}, p_{j}\right)$ with $p_{i}<p_{j}$ cannot constitute a pure equilibrium. It is not optimal to bid equal to firm $j$ 's bid, either. Provided that the offer price is above marginal cost, any firm can increase its profits by undercutting the rival at an infinitesimally lower price, since this increases the probability of being called into operation without reducing the system marginal price. Likewise, $p_{i}=p_{j}<0$ cannot be an equilibrium, since any firm has always an incentive to raise its offer price. By raising $p_{i}$, firm $i$ reduces its expected generation losses. It may also reduce its income from stranded-cost repayments. But this last effect can be shown to be less important. Finally, both firms bidding at the common marginal cost cannot constitute an equilibrium because any firm can increase its expected profits by raising its offer-price: a higher price raises profits by a strictly positive amount, $\eta\left(\frac{1}{2}\right)$, when demand is 2 and leaves them unaffected, under other circumstances. In conclusion, there is no pure-strategy equilibrium. 
However, I can show that there is a unique symmetric mixed-strategy equilibrium for this game. In this symmetric equilibrium both firms use the same pricing strategy defined by an identical distribution function, $F^{*}(p)$, over a coincident

support, $[\underline{p}, \tilde{p}]$. Lemmas 1-3 below tell me what are the basic properties that have to be satisfied by the (common) support of the equilibrium strategy.

Lemma 1 In any symmetric mixed-strategy equilibrium, $\widetilde{p}=\bar{p}$.

Proof. Let $\widetilde{p}$ be the highest price in the common support and assume $\widetilde{p}<\bar{p}$. It is easy to check that playing $\bar{p}$ any firm obtains a higher expected payoff than playing $\widetilde{p}$ in the amount of $(\bar{p}-\widetilde{p})(1-\pi) \frac{\pi}{2}>0$. Q.E.D.

That is, the (regulated) maximum price, $\bar{p}$, is always the upper bound of the firms' strategy in equilibrium.

Lemma 2 In any symmetric mixed-strategy equilibrium, $\underline{p} \geq 0$.

Proof. For all $p_{i}<0$ I have that $\Pi_{i}^{\prime}\left(p_{i}\right)>0$, irrespective of $p_{j}$. This implies that any price below marginal cost cannot be part of the equilibrium strategy. Q.E.D.

From this I conclude that no firm bids at prices below marginal cost.

\section{Lemma 3}

(a) In a symmetric mixed-strategy equilibrium, no offer price $\underline{p}<p<\bar{p}$, will be played with positive probability by any player, i.e., there are no interior mass points in the common support $[\underline{p}, \bar{p}]$. 
(b) In a symmetric mixed-strategy equilibrium, $\operatorname{int}\left(\operatorname{supp} F^{*}(p)\right)$ is connected, i.e., there are no gaps in the support of the players' strategies.

Proof. (a) I start by showing that if $\widehat{p} \in \operatorname{int}\left(\operatorname{supp} F^{*}(p)\right)$ is played with positive probability by some firm, $\widehat{p}$ is not played with positive probability by the other firm. Let $\widehat{p} \in \operatorname{int}\left(\operatorname{supp} F^{*}(p)\right)$ be an offer price which is played with positive probability by the firm $i$, i.e., $\Delta F^{*}(\widehat{p})=F^{*}(\widehat{p})-\lim _{x \uparrow 0} F^{*}(\widehat{p}-x)>0$. Since the number of mass points in $\operatorname{supp} F^{*}(p)$ must be countable, there is an $\varepsilon>0$ arbitrarily small such that $\widehat{p}-\varepsilon$ is named with zero probability by the firm $i$. The expected profits of firm $j$ when it sets a price $\widehat{p}$ with positive probability are lower than its profits when it undercuts $\widehat{p}$ to $\widehat{p}-\varepsilon(\varepsilon$ sufficiently small) in an amount equal to:

$$
\Delta F^{*}(\widehat{p}) \frac{\pi}{2}(\widehat{p}-\pi \varepsilon)>0 .
$$

The difference between bidding at $\widehat{p}$ and bidding at $\widehat{p}-\varepsilon$, is that in the former case, given a tie, firm $j$ is ranked below firm $i$ with probability $1 / 2$, while in the latter case firm $j$ is always ranked below firm $i$ when firm $i$ plays $\widehat{p}$.

I next show that if $\widehat{p} \in \operatorname{int}\left(\operatorname{supp} F^{*}(p)\right)$ is played with positive probability by any firm, any offer price exceeding $\widehat{p}$ by the other player is bounded away from $\widehat{p}$. As before, let $\widehat{p} \in \operatorname{int}\left(\operatorname{supp} F^{*}(p)\right)$ be an offer price which is played with positive probability by firm $i$. Since the number of mass points in $\operatorname{supp} F^{*}(p)$ must be countable, there is an $\varepsilon>0$ arbitrarily small such that $\widehat{p}+\varepsilon$ is named with zero probability by firm $i$. Consider now the payoff of firm $j$ who plays $\widehat{p}+\varepsilon$. The expected profits of firm $j$ when it sets a price $\widehat{p}$ are higher than its profits when it bids at $\widehat{p}+\varepsilon$, for $\varepsilon$ arbitrarily small, with positive probability, in an amount equal 
to:

$$
\Delta F^{*}(\widehat{p}) \frac{\pi}{2}(\widehat{p}-(1-\pi) \varepsilon)>0,
$$

so firm $j$ prefers to tie with firm $i$ rather than setting $\widehat{p}+\varepsilon$ ( $\varepsilon$ sufficiently small). The difference between bidding at $\widehat{p}$ and bidding at $\widehat{p}+\varepsilon$ is that at the last price firm $j$ is always ranked above firm $i$ when firm $i$ plays $\widehat{p}$. Given the strict inequality in equation (24) and by continuity, there exists $\tau>0$ sufficiently small, such that for all $\varepsilon \in(0, \tau)$ firm $j$ obtains a strictly higher payoff playing $\widehat{p}$ than playing $\widehat{p}+\varepsilon$. Therefore, any offer price which forms part of firm $j$ 's strategy and is not less than $\widehat{p}$ must be higher than $\widehat{p}+\tau$, i.e., firm $j$ never names a price $p \in(\widehat{p}, \widehat{p}+\tau)$. Consequently, firm $i$ 's optimal response is to shift its mass point from $\widehat{p}$ to $\hat{p}+\varepsilon$, with $\varepsilon \in(0, \tau)$ (since this increases its average price without reducing its sales) which contradicts the existence of a mass point at $\widehat{p}$.

(b) A set is connected if it is not the union of two non-empty disjoint closed subsets. Since $\operatorname{int}\left(\operatorname{supp} F^{*}(p)\right)$ is a subset of $\Re$, then $\operatorname{int}\left(\operatorname{supp} F^{*}(p)\right)$ is connected if and only if it is an interval. Let $\left(p_{a}, p_{b}\right)$ be the largest gap in $\operatorname{int}\left(\operatorname{supp} F^{*}(p)\right)$ and let $\left\{p_{g}\right\}$ and $\left\{p_{s}\right\}$ be two sequences of prices converging to $p_{a}$ and $p_{b}$, respectively. From the previous lemma, $F^{*}(p)$ contains no atoms in the interior of its support which implies that $\lim _{p_{g} \rightarrow p_{a}} F^{*}\left(p_{g}\right)=\lim _{p_{s} \rightarrow p_{b}} F^{*}\left(p_{s}\right)$, and thus that $F^{*}(p)$ is constant for any $p \in\left(p_{a}, p_{b}\right)$. This implies that $p_{a}=p_{b}$ because, otherwise, any firm would deviate by shifting density from $p=p_{a}$ to prices in $\left(p_{a}, p_{b}\right)$, since this does not involve the loss of any customer, and implies strictly greater expected revenues per customer. Q.E.D.

Proposition 4 There is a unique symmetric equilibrium in mixed strategies defined by the distribution function $F^{*}(p)$, which represents the equilibrium pricing strategy of each firm, where $p \in[\underline{p}, \bar{p}]$ and $\underline{p}$ is given by (26). 


$$
\begin{aligned}
F^{*}(p)= \begin{cases}\ln \left(e(p / \bar{p})^{\frac{1}{4}}\right) & \text { when } \pi=\frac{1}{2} \\
\left(\frac{1-\pi}{1-2 \pi}\right)(p / \bar{p})^{\frac{1-2 \pi}{2}}+\frac{\pi}{2 \pi-1} & \text { when } \pi \neq \frac{1}{2},\end{cases} \\
0<\underline{p}=\left\{\begin{array}{lll}
\bar{p}\left(\frac{1}{e}\right)^{4} & \text { when } & \pi=\frac{1}{2} \\
\bar{p}\left(\frac{\pi}{1-\pi}\right)^{\frac{2}{1-2 \pi}} & \text { when } & \pi \neq \frac{1}{2} .
\end{array}\right.
\end{aligned}
$$

Proof. From the previous lemmas I know that in a symmetric mixed-strategy equilibrium both firms use the same pricing strategy defined by an identical distribution function, $F^{*}(p)$, over a coincident and connected support, $[\underline{p}, \bar{p}]$ and no player plays any price $p<\bar{p}$ with positive probability.

Since $F^{*}(\bar{p})=1$, firm $i$ 's expected payoff from playing $\bar{p}$ is:

$$
\Pi_{i}(\bar{p})=\bar{p}(1-\pi) \frac{\pi}{2}+\left(S-(2-\pi)\left(\pi \int_{\underline{p}}^{\bar{p}} \rho f^{*}(\rho) d \rho-p^{*}\right)\right) \frac{1}{2} .
$$

The expected payoff to player $i$ of playing $p \in[\underline{p}, \bar{p}]$ is:

$$
\begin{aligned}
\Pi_{i}(p)= & \frac{\pi}{2}\left(p\left(\pi+F^{*}(p)(1-2 \pi)\right)+(1-\pi) \int_{p}^{\bar{p}} \rho f^{*}(\rho) d \rho\right) \\
& +\left(S-(2-\pi)\left(\pi \int_{\underline{p}}^{p} \rho f^{*}(\rho) d \rho-p^{*}\right)\right) \frac{1}{2} .
\end{aligned}
$$

In a mixed-strategy equilibrium, it must be the case that,

$$
\Pi_{i}(p)=\Pi_{i}(\bar{p}), \forall p \in[\underline{p}, \bar{p}]
$$

Given that $F^{*}(p)$ is continuous in $[\underline{p}, \bar{p}]$ (lemma $3(\mathrm{a})$ ) and $[\underline{p}, \bar{p}]$ is connected 
(lemma 3(b)), equation (29) implies that,

$$
\Pi_{i}^{\prime}(p)=\frac{\pi}{2}\left(\pi+(1-2 \pi) F^{*}(p)\right)-\pi p f^{*}(p)=0, \forall p \in(\underline{p}, \bar{p}) .
$$

Rearranging terms I have that,

$$
f^{*}(p)-\frac{(1-2 \pi)}{2} \frac{F^{*}(p)}{p}=\frac{\pi}{2 p}
$$

Solving this first-order differential equation with the boundary condition that $F^{*}(\bar{p})=1$, I have that:

$$
F^{*}(p)= \begin{cases}\ln \left(e(p / \bar{p})^{\frac{1}{4}}\right) & \text { when } \pi=\frac{1}{2} \\ \left(\frac{1-\pi}{1-2 \pi}\right)(p / \bar{p})^{\frac{1-2 \pi}{2}}+\frac{\pi}{2 \pi-1} & \text { when } \pi \neq \frac{1}{2}\end{cases}
$$

Then, solving out $F^{*}(\underline{p})=0$, I obtain:

$$
\underline{p}= \begin{cases}\bar{p}\left(\frac{1}{e}\right)^{4} & \text { when } \pi=\frac{1}{2} \\ \bar{p}\left(\frac{\pi}{1-\pi}\right)^{\frac{2}{1-2 \pi}} & \text { when } \pi \neq \frac{1}{2} .\end{cases}
$$

This concludes the existence part of this proof. Uniqueness of symmetric equilibrium follows immediately from the fact that the first differential equation in (31) has a unique solution satisfying the boundary constraint that $F^{*}(\bar{p})=1$. Q.E.D.

Proposition 5 There is no asymmetric mixed-strategy equilibrium for this game. 
Proof. From Proposition 3 I know that it cannot be the case that, in equilibrium, firms set prices according to degenerated distribution functions. A similar argument to the one used in Lemma 3 can be used to rule out mass points and gaps in the support of any asymmetric mixed-strategy equilibrium strategy. Furthermore, I have that the expected profit function for each firm is identical. Then, to show that there are no asymmetric mixed-strategy equilibria it is sufficient to prove that firms set prices according to a common support, $[\underline{p}, \widetilde{p}]$, with $\underline{p}<\widetilde{p}$. From Proposition $3 \underline{p}_{i}<\bar{p}$ for $i=1$, 2. Suppose $\underline{p}_{i}<\underline{p}_{j}<\bar{p}$, then $\Pi_{i}\left(\underline{p}_{i}\right)$ increases for values of $p$ such that $\underline{p}_{i}<p \leq \underline{p}_{j}$ since $F_{j}^{*}(p)$ is constant for prices in that interval. Hence $\underline{p}_{i}=\underline{p}_{j}$. Suppose now that $\bar{p}_{i}>\bar{p}_{j}$. Then, firm $i$ is the only competitor setting a price $p \in\left(\bar{p}_{j}, \bar{p}_{i}\right)$ as part of its strategy. But, in this case, firm $i$ has an incentive to shift probability from $p$ to $\bar{p}_{i}$ as this increases its expected payoff by $\frac{1}{2} \pi(1-\pi)\left(\bar{p}_{i}-p\right)>0$. This is true for all $p \in\left(\bar{p}_{j}, \bar{p}_{i}\right)$, which contradicts the non-existence of gaps in the equilibrium distribution function. Hence $\bar{p}_{i}=\bar{p}_{j}$. In conclusion, only symmetric mixed-strategy equilibria exist for this game. Q.E.D.

Summing up, from Propositions 3, 4 and 5, I conclude that there is a unique equilibrium for the full game in which each firm sets prices according to a common, continuous and strictly increasing distribution function $F^{*}(p)$ over a coincident and connected support $[\underline{p}, \bar{p}]$.

Let $E^{*}[p]=\int_{\underline{p}}^{\bar{p}} p d F^{*}(p)$ denote the expected price of the game associated to the equilibrium strategy, $F^{*}(p)$. Then, I can show that:

Corollary 1 The equilibrium expected price, $E^{*}[p]=\int_{\underline{p}}^{\bar{p}} p d F^{*}(p)$, is a decreasing function of $\pi$. 
Proof. It can be shown that

$$
E^{*}[p]=\int_{\underline{p}}^{\bar{p}} p d F^{*}(p)=\bar{p}\left(\frac{1-\pi}{3-2 \pi}\right)\left[1-\left(\frac{\pi}{1-\pi}\right)^{\frac{3-2 \pi}{1-2 \pi}}\right] .
$$

Then,

$$
\begin{aligned}
\frac{\partial E^{*}[p]}{\partial \pi}=\bar{p}\{ & {\left[\left(\frac{2}{2 \pi-1}\right)^{2}\left(\frac{1-\pi}{2 \pi-3}\right) \ln \frac{\pi}{1-\pi}+\frac{1}{(2 \pi-1) \pi}\right]\left(\frac{\pi}{1-\pi}\right)^{\frac{3-2 \pi}{1-2 \pi}} } \\
& \left.+\left(\frac{1}{2 \pi-3}\right)^{2}\left[\left(\frac{\pi}{1-\pi}\right)^{\frac{3-2 \pi}{1-2 \pi}}-1\right]\right\}<0, \text { for all } \pi \in[0,1]
\end{aligned}
$$

Q.E.D.

Corollary 1 implies that the larger is the probability of low demand, the more competitive becomes the market, so that, the lower are the expected prices. Whenever $\pi$ raises, the probability of being out of the merit order increases for any given price, in which case both firms will tend to submit lower bids. In the limit, when $\pi$ equals 1 , I have that $F^{*}(\underline{p})=1$, so that, both firms bid always in equilibrium at the lowest possible price in the support, $\underline{p}$. Furthermore, I have that

$$
\lim _{\pi \rightarrow 1} \underline{p}=0
$$

which implies that, when $\pi$ equals 1 , both firms set marginal costs in equilibrium. 


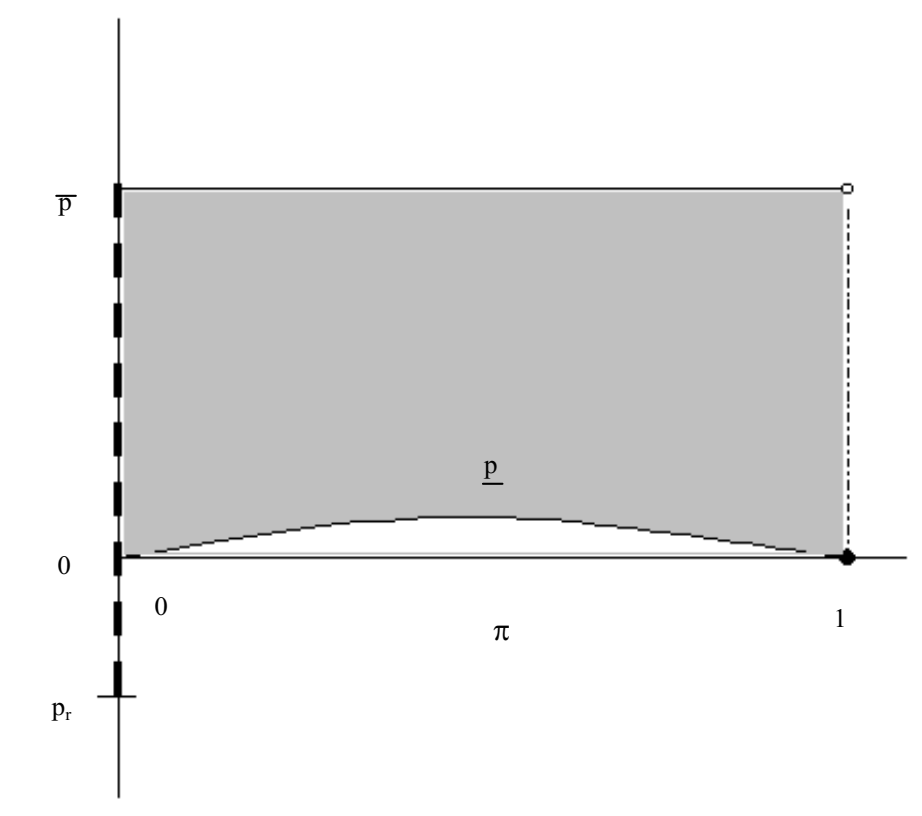

Figure 1: Range of equilibrium prices. This figure plots the range of equilibrium prices as a function of $\pi$. When $\pi$ equals 1 the unique price in equilibrium is the marginal cost. Any price in the interval $\left[\mathrm{p}_{\mathrm{r}}, \overline{\mathrm{p}}\right]$ can be the system marginal price when $\pi$ equals zero. The range of equilibrium prices is represented by the interval [p, p] if $0<\pi<1$.

A fall in $\pi$ produces two opposite effects. First, when $\pi$ diminishes the probability of being out of the merit order declines for any given price, so that, this would lead firms to raise their offer prices. On the other hand, when $\pi$ falls, the net benefits of raising the system marginal price decrease. This last effect partly mitigates the incentive to raise the offer price. In the limit, when $\pi$ equals 0 , those two effects offset perfectly. Consequently, both firms supply the market at their full capacities and the net benefit of raising the system marginal price is zero: what a firm earns via generation when the system marginal price raises is exactly offset by what it losses in stranded-cost payments. Therefore, firms will be indifferent between any price $p \in\left[p_{r}, \bar{p}\right]$. This is illustrated in Figure 1 where I depict the range of equilibrium prices as a function of the demand distribution. When 
$\pi$ equals 1 I have that a pure-strategy equilibrium exists with both firms bidding at marginal cost. Any price in the interval $\left[p_{r}, \bar{p}\right]$ can be the system marginal price when $\pi$ equals zero. Finally, whenever $0<\pi<1$, I get a mixed-strategy equilibrium in which both firms use the same pricing strategy defined by $F^{*}(p)$, over the common support, $[\underline{p}, \bar{p}]$.

To conclude this section, I compare the equilibrium of my symmetric game with stranded cots with the equilibrium of an otherwise identical game without stranded costs.

Let $\widehat{F}(p)$ be the common equilibrium pricing strategy of each firm in a pool market without stranded costs. ${ }^{17}$ Then, I can show the main result:

Corollary $2 F^{*}(p) \geq \widehat{F}(p)$, for all $p \in[\underline{p}, \bar{p}]$.

From the previous corollary it results that the generators' common pricing strategy in a pool market without stranded costs first-order stochastically dominates the generators' strategy in an otherwise identical pool market with stranded costs. [See Figure 2]. That is, generators in a pool market without stranded costs submit higher prices with greater probability than they do in a market with stranded costs. Therefore, starting from a situation without stranded-cost repayments, these costs necessarily encourage overall competition.

\footnotetext{
${ }^{17}$ If we impose that $\theta_{1}=\theta_{2}=0$, and allow for different marginal costs among firms, our model coincides with von der Fehr and Harbord (1993)'s model.
} 


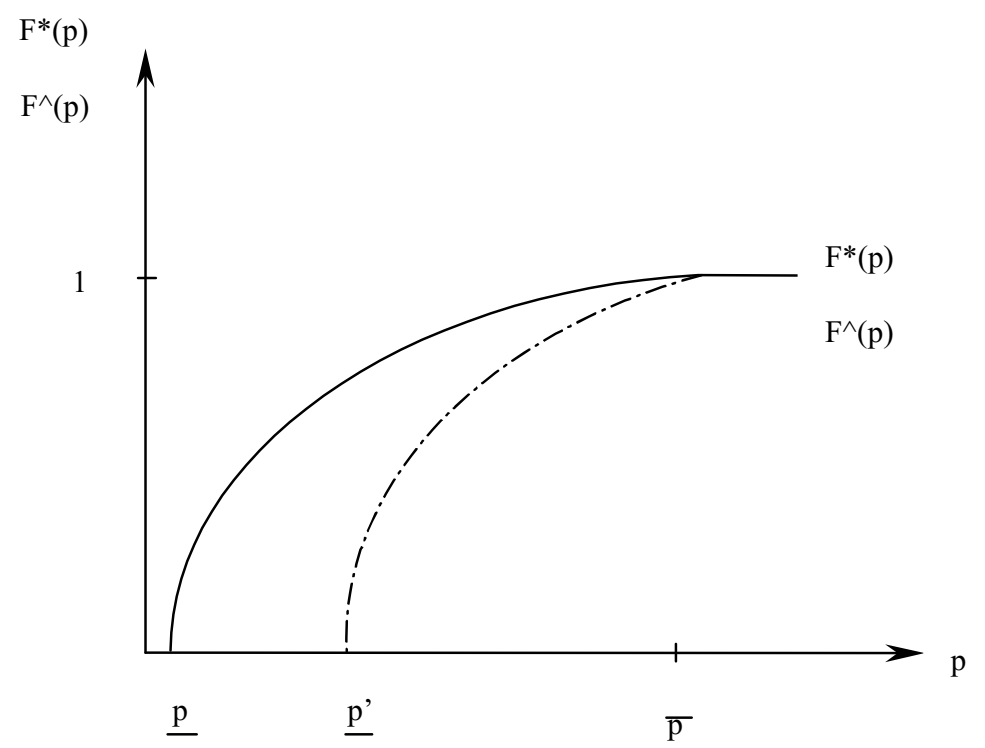

Figure 2: Equilibrium pricing strategies. This figure plots the equilibrium pricing strategies in a pool market with stranded costs, denoted by $\mathrm{F}^{*}(\mathrm{p})$; and in an otherwise identical pool market without stranded costs, represented by $\mathrm{F}^{\wedge}(\mathrm{p})$.

\section{The Analysis: Extensions}

\subsection{Asymmetric Stranded-Cost Sharing Rules}

In what follows I assume that $\theta_{2}<\theta_{1}$, that is, stranded-cost recovery payoffs are shared among generators asymmetrically. Since $\sum_{i=1}^{2} \theta_{i}=1$ then I have that $0<\theta_{2}<1 / 2<\theta_{1}<1$. As I show below, generators' price incentives strongly depend on $\eta\left(\theta_{i}\right)$, so that, the sign and magnitude of the parameter $\eta\left(\theta_{i}\right)$ is crucial in order to identify the equilibria in the following sub-sections. First up, I consider conditions under which I find pure-strategy equilibria, and subsequently I identify mixed-strategy equilibria. 


\subsubsection{High-Demand Periods}

I start by dealing with the case in which, with probability one, demand is equal to 2 , i.e., $\pi=0$. Pure-strategy equilibria exist in all of which the system marginal price equals the highest admissible price.

Proposition 6 If $\pi=0$ and $\theta_{2}<\theta_{1}$, then there exist pure-strategy equilibria, in all of which generator 2 determines the system marginal price offering to supply at the highest admissible price, $\bar{p}$.

Proof. Suppose that in equilibrium $p_{1}>p_{2}$. Since $\pi=0$ then I have that

$$
\Pi_{1}^{\prime}\left(p_{1}\right)=\eta\left(\theta_{1}\right)=\left\{\begin{array}{lll}
1-2 \theta_{1} & <0 & \text { if } p_{1} \in\left(p_{r}, \bar{p}\right) \\
1 & >0 & \text { if } p_{1}<p_{r} .
\end{array}\right.
$$

Hence, firm 1 will alter its price so that $p_{1}>p_{2}$ cannot be an equilibrium. Likewise, $p_{1}=p_{2}$ cannot be an equilibrium either since $\eta\left(\theta_{2}\right)=1-2 \theta_{2}>0$, so that $\Pi_{2}^{\prime}\left(p_{2}\right)>0$, and hence, firm 2 can increase its profit by increasing its bid. Then, it must hold that, in equilibrium, $p_{2}>p_{1}$. Since $\left.\Pi_{2}\left(p_{2}\right)\right|_{p_{2}>p_{1}}$ is strictly increasing in its argument I can conclude that generator 2 will bid in equilibrium at the highest admissible price. Furthermore, because both generators always supply its total capacity, generator 2 has no incentive to deviate undercutting generator 1 , whatever firm 1's bid. Q.E.D.

In high demand periods both generators are despatching its total capacity. Since I have that $\eta\left(\theta_{2}\right)>0$ and $\eta\left(\theta_{1}\right)<0$ for all $p \in\left[p_{r}, \bar{p}\right]$, it implies that generator 1's expected payments are decreasing with its own bid; meanwhile generator 2's expected profits are increasing in its own offer price. Therefore, pure-strategy 
equilibria exist, in all of which the generator with lower proportion of SCR share (generator 2) will always determine the system marginal price bidding at the highest admissible price, $\bar{p}$. Generator with the higher proportion of SCR share (generator 1) is indifferent between any offer price lower than rival's bid. Furthermore, since both generators always supply its total capacity, generator 2 has no incentive to deviate undercutting generator 1, irrespective of firm 1's bid.

\subsubsection{Low-Demand Periods}

In this scenario I deal with the case where, with probability one, demand is one, i.e., $\pi=1$. As in the symmetric case I find an unique equilibrium outcome in which both generators offer to supply at marginal cost and only one of them supply the whole demand.

Proposition 7 If $\pi=1$ and $\theta_{2}<\theta_{1}$, then there exists a unique pure-strategy equilibrium, in which the system marginal price equals marginal cost and only one generator supplies the market.

Proof. The argument to prove this proposition is equivalent to that found in section 4.2 .

Because of the structure of stranded-cost recovery payments, in the equilibrium both firms will earn positive profits strictly bigger than zero but asymmetric, that is, generator with a lower proportion of SCR share will obtain lower payoffs than generator with a higher proportion of SCR share.

\subsubsection{Fluctuating-Demand Periods}

In this section I concentrate on the case in which both low demand and high demand can occur with positive probability, i.e., $0<\pi<1$, so that either generator 
can be the marginal operating unit with positive probability regardless of its bid.

The sign of $\eta\left(\theta_{i}\right)$, the firm $i$ 's net marginal benefit of altering $p_{i}$, plays a crucial role in the determination of the generators' equilibrium strategies since pricing incentives depend on it. Differing from the symmetric case, in which I have that $\eta\left(\frac{1}{2}\right)$ is strictly positive for all $\pi \in(0,1)$, in the asymmetric case I have that, while $\eta\left(\theta_{2}\right)$ remains positive for all $\pi \in(0,1)$, the sign of $\eta\left(\theta_{1}\right)$ can be positive, negative or even zero, depending on the current values of $\pi$ and $\theta_{i}$ 's. This is illustrated in Figure 3 where I depict the regions in which, provided $p_{1}$ $\in\left[p_{r}, \bar{p}\right]$, firm 1's net marginal benefit presents a positive, zero or negative sign as a function of demand distribution, $\pi$, and proportion of SCR shares among firms, $\theta_{i}{ }^{\prime}$ s. ${ }^{18}$ It can be observed in Figure 3 that, remaining constant $\theta_{1}$, a change in demand distribution, $\pi$, can alter dramatically the pricing incentives for firm 1. From equation (13) I know that $\eta\left(\theta_{1}\right)$ is a continuous and decreasing function of $\pi$. Starting from a situation of positive net marginal benefit, a fall in $\pi$ relaxes firm 1's incentives to increase its offer price. In fact, since I have that $\left.\eta\left(\theta_{1}\right)\right|_{\pi=0}<0$ and $\left.\eta\left(\theta_{1}\right)\right|_{\pi=1}>0$ for all $\theta_{1} \in(1 / 2,1)$ then I get that, for any $\theta_{1}$, I can find values of $\pi$ low enough such that firm 1's net marginal benefit of raising $p_{1}$ becomes negative $\left(\eta\left(\theta_{1}\right)<0\right)$, so that, firm 1 's pricing incentive is now to reduce its offer price. Note also that a decrease in the degree of asymmetry in the SCR shares (a fall in $\theta_{1}$ ) increases the range of demand distributions which makes positive the firm $i$ 's net marginal benefit of altering $p_{i}, \eta\left(\theta_{1}\right)$.

\footnotetext{
${ }^{18}$ Remember that $\eta\left(\theta_{i}\right)=1$, for all $p_{i}<p_{r}, i=1,2$.
} 


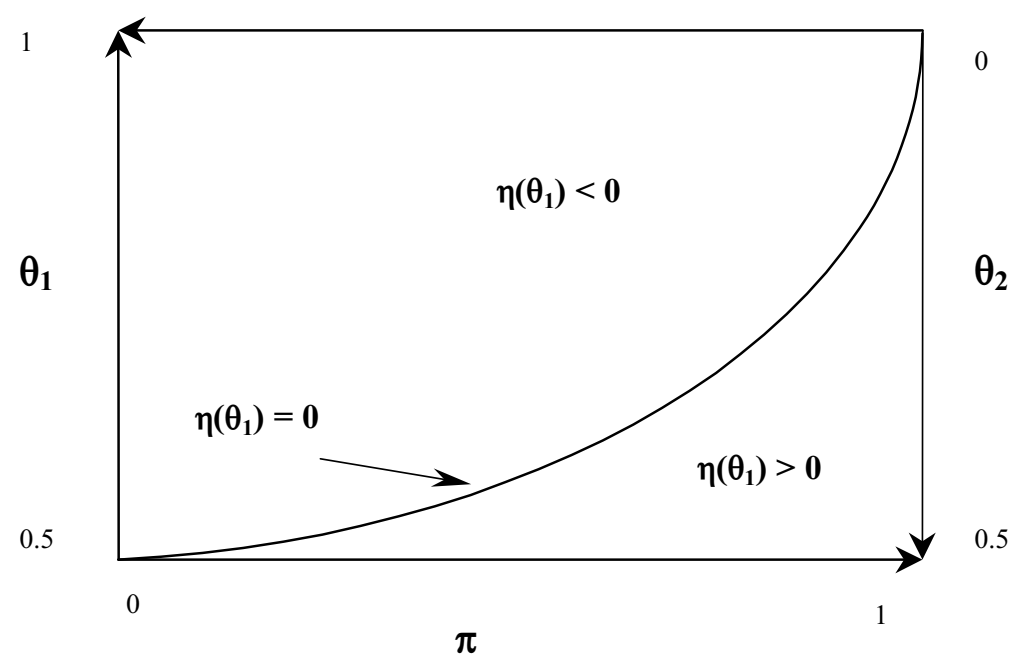

Figure 3: Values of parameter $\eta\left(\theta_{1}\right)$. This figure represents the regions in which firm 1's net marginal benefit is positive, negative or zero; as a function of the probability of low demand $(\pi)$ and the SCR shares among firms $\left(\theta_{1}\right.$ and $\left.\theta_{2}\right)$.

Therefore, I distinguish three cases in order to deal the analysis of the types of equilibria in the game:

(a) Case I: $\eta\left(\theta_{1}\right)>0$, where, provided firm 1 sets the system marginal price, it always has an incentive to raise, at least marginally, its offer price. The cases in which this assumption holds are restricted for the values of $\theta_{1}$ and $\pi$ in the following manner,

$$
\eta_{\theta_{1}}>0 \Leftrightarrow \theta_{1}<\frac{1}{2-\pi} .
$$

(b) Case II: $\eta\left(\theta_{1}\right)=0$, if firm 1 is the marginal operating unit, its benefits are not altered by changes on its own offer price.

(c) Case III: $\eta\left(\theta_{1}\right)<0$, where the firm 1 always wants to decrease its offer price in order to maximize its profits. 
I proceed to analyze the types of equilibria in the game under the three possible cases.

- Case I: $\boldsymbol{\eta}\left(\theta_{1}\right)>\mathbf{0}$

Under the current case there does not exist pure-strategy equilibrium. However, I can show that a unique mixed-strategy equilibrium does exist and has very intuitive properties.

Proposition 8 If $0<\pi<1$ and $\eta\left(\theta_{1}\right)>0$, then there does not exist an equilibrium in pure strategies for this game.

Proof. Similar to that one of Proposition (3) when substituting both equation (21) and equation (22), which hold in the symmetric case, by the equation (39) and equation (40), respectively:

$$
\begin{gathered}
0<\eta\left(\theta_{i}\right)= \begin{cases}1-(2-\pi) \theta_{i} & \text { if } p_{i} \in\left[p_{r}, \bar{p}\right) \\
1 & \text { if } p_{i}<p_{r},\end{cases} \\
0<\Pi_{i}^{\prime}\left(p_{i}\right)= \begin{cases}\pi \eta\left(\theta_{i}\right) & \text { if } p_{i} \in\left[p_{r}, \bar{p}\right) \\
\pi & \text { if } p_{i}<p_{r},\end{cases}
\end{gathered}
$$

which applies in this case. Q.E.D.

The intuition for the proposition above is comparable to that one developed in Proposition (3). I can show that there is a unique equilibrium in mixed strategies for this game in which each firm set prices according to continuous and strictly 
increasing distribution functions, $F_{i}^{*}(p)$ for $i=1,2$, over a coincident interval, except that firm 2 names the uppermost price with positive probability. Following lemmas below establish what are the attributes that have to satisfy the respective supports in any pair of equilibrium strategies.

\section{Lemma 4}

(a) $\bar{p}_{i} \leq \bar{p}, \quad i=1,2$.

(b) It is impossible for both firms to name identical supreme, i.e., $\bar{p}_{i}=\bar{p}_{j}$, with positive probabilities.

(c) Suppose that either $\bar{p}_{2}>\bar{p}_{1}$, or $\bar{p}_{2}=\bar{p}_{1}$ and $\bar{p}_{1}$ is named with probability zero. Then, in any equilibrium $\bar{p}_{2}=\bar{p}$.

Proof. (b) Suppose $\bar{p}_{i}=\bar{p}_{j}=\widehat{p}$ and $\widehat{p}$ is played with positive probability by the firm $i$, i.e., $\Delta F_{i}^{*}(\widehat{p})=F_{i}^{*}(\widehat{p})-\lim _{x \uparrow 0} F_{i}^{*}(\widehat{p}-x)>0$. Since the number of mass points in $\operatorname{supp} F_{i}^{*}(\widehat{p})$ must be countable, there is an $\varepsilon>0$ arbitrarily small such that $\widehat{p}-\varepsilon$ is named with zero probability by the firm $i$. The expected profits of firm $j$ when it sets the price $\widehat{p}$ with positive probability are lower than its profits when it undercuts $\widehat{p}$ to $\widehat{p}-\varepsilon$ ( $\varepsilon$ sufficiently small $)$ in an amount equal to:

$$
\Delta F_{i}^{*}(\widehat{p}) \frac{\pi}{2}\left(\widehat{p}-2 \eta\left(\theta_{j}\right) \varepsilon\right)>0
$$

The difference between bidding at $\widehat{p}$ and bidding at $\widehat{p}-\varepsilon$, is that in the former case, given a tie, firm $j$ is ranked below firm $i$ with probability $1 / 2$, while in the latter case firm $j$ is always ranked below firm $i$ when firm $i$ plays $\widehat{p}$. Q.E.D. 
(c) Since $\bar{p}_{2}$ has been defined as upper bound of $\operatorname{supp} F_{2}^{*}$, it implies that $F_{2}^{*}\left(\bar{p}_{2}\right)=1$. Hence, $\Pi_{2}\left(\bar{p}_{2}\right)$ is strictly increasing in its argument, and so, it attains a maximum at $\bar{p}$. Q.E.D.

Lemma 5 In any equilibrium $\underline{p}_{i}=\underline{p}_{j}=\underline{p} \geq 0$.

Proof. First I prove that $\underline{p}_{i}=\underline{p}_{j}=\underline{p}$. From Proposition (8) $\underline{p}_{i}<\bar{p}$ for $i=$ 1,2. Suppose $\underline{p}_{i}<\underline{p}_{j}<\bar{p}$, then $\Pi_{i}\left(\underline{p}_{i}\right)$ increases for values of $p$ such that $\underline{p}_{i}<$ $p \leq \underline{p}_{j}$ since $F_{j}^{*}(p)$ is constant for prices in that interval. Hence $\underline{p}_{i}=\underline{p}_{j}=\underline{p}$. To complete the proof, I need to show that $\underline{p} \geq 0$. I have that $\Pi_{i}^{\prime}\left(p_{i}\right)>0$, for all $p_{i}<0$ irrespective of $p_{j}$. Thus any price below marginal cost cannot be part of an equilibrium strategy. Q.E.D.

\section{Lemma 6}

(a) In any equilibrium, no offer price $\underline{p}<p<\bar{p}$, will be played with positive probability by any player, i.e., there are no interior mass points in the support of players' strategies.

(b) In any equilibrium, $\operatorname{int}\left(\operatorname{supp} F_{i}^{*}(p)\right)$ is connected, for all $i=1,2$, i.e., there are no gaps in the support of players' strategies.

Proof. (a) Similar argument to that one of lemma 3(a) when substituting $F^{*}(p)$, which applies for the symmetric case, by $F_{i}^{*}(p)$, and equations (23) and (24) by the below equations (42) and (43), respectively:

$$
\begin{gathered}
\Delta F_{i}^{*}(\widehat{p}) \frac{\pi}{2}\left(\widehat{p}-2 \eta\left(\theta_{j}\right) \varepsilon\right)>0, \\
\Delta F_{i}^{*}(\widehat{p}) \frac{1}{2}\left(\pi \widehat{p}-2(1-\pi) \eta\left(\theta_{j}\right) \varepsilon\right)>0 .
\end{gathered}
$$


(b) A set is connected if it is not the union of two non-empty disjoint closed subsets. Since $\operatorname{int}\left(\operatorname{supp} F_{i}^{*}(p)\right)$ is a subset of $\Re$ for all $i$, then $\operatorname{int}\left(\operatorname{supp} F_{i}^{*}(p)\right)$ is connected if and only if it is an interval. For any given $i$, let $\left(p_{a i}, p_{b i}\right)$ be the largest gap in $\operatorname{int}\left(\operatorname{supp} F_{i}^{*}(p)\right)$ and let $\left\{p_{g}\right\}$ and $\left\{p_{s}\right\}$ be two sequences of prices converging to $p_{a i}$ and $p_{b i}$, respectively. From the previous lemma, $F_{i}^{*}(p)$ contains no atoms in the interior of its support which implies that $\lim _{p_{g} \rightarrow p_{a i}} F_{i}^{*}\left(p_{g}\right)=$ $\lim _{p_{s} \rightarrow p_{b i}} F_{i}^{*}\left(p_{s}\right)$, and thus that $F_{i}^{*}(p)$ is constant for any $p \in\left(p_{a i}, p_{b i}\right)$. This implies that $p_{a i}=p_{b i}$ because, otherwise, any firm would deviate by shifting density from $p=p_{a i}$ to prices in $\left(p_{a i}, p_{b i}\right)$, since this does not involve the loss of any customer, and implies strictly greater expected revenues per customer. Q.E.D.

From lemmas 4-6 I know that in the equilibrium at most one player who plays $\bar{p}$ with positive probability, that no player plays any price $p<\bar{p}$ with positive probability, and that both players' mixed strategies have full support on $[\underline{p}, \bar{p}]$. I then obtain the following result:

Proposition 9 There exists an unique equilibrium in mixed strategies defined by two distribution functions $F_{1}^{*}(p)$ and $F_{2}^{*}(p)$ representing the equilibrium pricing strategies of firm 1 and firm 2 , respectively, where $p \in[\underline{p}, \bar{p}]$, and $\underline{p}$ is given by (46).

$$
\begin{gathered}
F_{1}^{*}(p)= \begin{cases}\ln \left(e(p / \bar{p})^{\frac{2-3 \theta_{2}}{2}}\right) & \text { when } \quad \pi=\frac{1}{2} \\
\frac{\pi}{1-2 \pi}\left(\frac{1-\pi}{\pi}\right)(p / \bar{p})^{\eta\left(\theta_{2}\right) \frac{1-2 \pi}{\pi}}+\frac{\pi}{2 \pi-1} & \text { when } \quad \pi \neq \frac{1}{2},\end{cases} \\
F_{2}^{*}(p)= \begin{cases}\ln \left(e^{\left.\frac{2-3 \theta_{1}}{2-3 \theta_{2}}(p / \bar{p})^{\frac{2-3 \theta_{1}}{2}}\right)}\right. & \text { when } \quad p<\bar{p} \text { and } \pi=\frac{1}{2} \\
\frac{\pi}{1-2 \pi}\left(\frac{1-\pi}{\pi}\right)^{\frac{\eta\left(\theta_{1}\right)}{\eta\left(\theta_{2}\right)}}(p / \bar{p})^{\eta\left(\theta_{1}\right) \frac{1-2 \pi}{\pi}}+\frac{\pi}{2 \pi-1} & \text { when } p<\bar{p} \text { and } \pi \neq \frac{1}{2},\end{cases}
\end{gathered}
$$




$$
F_{2}^{*}(\bar{p})=1,
$$

$$
0<\underline{p}=\left\{\begin{array}{lll}
\bar{p}\left(\frac{1}{e}\right)^{\frac{2}{2-3 \theta_{2}}} & \text { when } & \pi=\frac{1}{2} \\
\bar{p}\left(\frac{\pi}{1-\pi}\right)^{\frac{\pi}{(1-2 \pi)} \frac{1}{\eta\left(\theta_{2}\right)}} & \text { when } & \pi \neq \frac{1}{2} .
\end{array}\right.
$$

Proof. Since $F_{1}(\bar{p})=1$, player 2 's expected payoff from playing $\bar{p}$ is:

$$
\Pi_{2}(\bar{p})=\bar{p}(1-\pi) \eta\left(\theta_{2}\right)+\left(S-(2-\pi)\left(\pi \int_{\underline{p}}^{\bar{p}} \rho f_{1}(\rho) d \rho-p^{*}\right)\right) \theta_{2} .
$$

The expected payoff to player 2 of playing $p \in[\underline{p}, \bar{p}]$ is:

$$
\begin{aligned}
\Pi_{2}(p)= & \eta\left(\theta_{2}\right)\left(p\left(\pi+F_{1}(p)(1-2 \pi)\right)+(1-\pi) \int_{p}^{\bar{p}} \rho f_{1}(\rho) d \rho\right) \\
& +\left(S-(2-\pi)\left(\pi \int_{\underline{p}}^{p} \rho f_{1}(\rho) d \rho-p^{*}\right)\right) \theta_{2} .
\end{aligned}
$$

In a mixed-strategy equilibrium, it must be the case that

$$
\Pi_{2}(p)=\Pi_{2}(\bar{p}), \text { for all } p \in[\underline{p}, \bar{p}] .
$$

Given that $F_{1}^{*}(p)$ is continuous in $[\underline{p}, \bar{p}]$ (lemma $6(\mathrm{a})$ ) and $[\underline{p}, \bar{p}]$ is connected (lemma 6(b)), equation (49) implies that,

$$
\Pi_{2}^{\prime}(p)=\eta\left(\theta_{2}\right)\left(\pi+(1-2 \pi) F_{1}^{*}(p)\right)-\pi p f_{1}^{*}(p)=0 \text {, for all } p \in(\underline{p}, \bar{p}) .
$$

Rearranging terms I have that, 


$$
f_{1}^{*}(p)-\eta\left(\theta_{2}\right) \frac{(1-2 \pi)}{\pi} \frac{F_{1}^{*}(p)}{p}=\eta\left(\theta_{2}\right) \frac{1}{p} .
$$

Solving this first-order differential equation with the boundary condition that $F_{1}^{*}(\bar{p})=1$, I have that:

$$
F_{1}^{*}(p)=\left\{\begin{array}{lll}
\ln \left(e(p / \bar{p})^{\frac{2-3 \theta_{2}}{2}}\right) & \text { when } & \pi=\frac{1}{2} \\
\frac{\pi}{1-2 \pi}\left(\frac{1-\pi}{\pi}\right)(p / \bar{p})^{\eta\left(\theta_{2}\right) \frac{1-2 \pi}{\pi}}+\frac{\pi}{2 \pi-1} & \text { when } & \pi \neq \frac{1}{2}
\end{array}\right.
$$

Then, solving out $F_{1}^{*}(\underline{p})=0$, I obtain:

$$
\underline{p}= \begin{cases}\bar{p}\left(\frac{1}{e}\right)^{\frac{2}{2-3 \theta_{2}}} & \text { when } \quad \pi=\frac{1}{2} \\ \bar{p}\left(\frac{\pi}{1-\pi}\right)^{\frac{\pi}{(1-2 \pi)} \frac{1}{\eta\left(\theta_{2}\right)}} & \text { when } \quad \pi \neq \frac{1}{2} .\end{cases}
$$

Employing the same procedure I obtain:

$$
\begin{aligned}
& F_{2}^{*}(p)= \begin{cases}\ln \left(e^{\frac{2-3 \theta_{1}}{2-3 \theta_{2}}}(p / \bar{p})^{\frac{2-3 \theta_{1}}{2}}\right) & \text { when } \quad p<\bar{p} \text { and } \pi=\frac{1}{2} \\
\frac{\pi}{1-2 \pi}\left(\frac{1-\pi}{\pi}\right)^{\frac{\eta\left(\theta_{1}\right)}{\eta\left(\theta_{2}\right)}}(p / \bar{p})^{\eta\left(\theta_{1}\right) \frac{1-2 \pi}{\pi}}+\frac{\pi}{2 \pi-1} & \text { when } \quad p<\bar{p} \text { and } \pi \neq \frac{1}{2}\end{cases} \\
& F_{2}^{*}(\bar{p})=1 .
\end{aligned}
$$

This concludes the existence part of this proof. As I already argued in the proof of Proposition 4 uniqueness of equilibrium follows immediately from the fact that the first differential equation in (51) has a unique solution satisfying the boundary constraint that $F_{1}^{*}(\bar{p})=1$. A similar argument can be used to prove uniqueness of firm 2's equilibrium strategy. Q.E.D. 
From Propositions 8 and 9 I conclude that there is a unique equilibrium for the full game in which each firm set prices according to continuous and strictly increasing distribution functions over a connected and identical support, $[\underline{p}, \bar{p}]$. It is interesting to notice the presence of an atom of positive probability in the distribution function of the lower-SCR share generator. Firm 2 names the uppermost price, $\bar{p}$, with positive probability. This mass point at $\bar{p}$, is an increasing function of the degree of asymmetry in the proportion of SCR shares and a decreasing function of $\pi$. The more asymmetric the SCR shares, the less tempted the lowerSCR share generator is to exploit its SCR payments. A fall in $\theta_{2}$ increases firm 2 's net marginal benefit of raising its offer price, so that, more probability mass is placed on higher prices. Likewise, a fall in $\pi$ increases the probability that both generators will be operating even if they offer to supply only at high prices. Thus, more probability mass is placed on higher prices, in which case both firms will tend to submit high bids. I also find that the lowest price in the support of the players' strategies, $\underline{p}$, is strictly greater than the marginal cost, and that this lowest price is a decreasing function of $\pi$ and an increasing function both of the degree of asymmetry in the SCR shares and the highest admissible price, $\bar{p}$. In particular, it can be shown that:

$$
\begin{gathered}
\lim _{\pi \rightarrow 0} \underline{p}=\bar{p}, \text { and } \\
\lim _{\pi \rightarrow 1} \underline{p}=0 .
\end{gathered}
$$

These limits represent the cases dealt in subsections 5.1.1 and 5.1.2, respectively.

Furthermore, from equation (52) and equation (54), I get,

Corollary $3 F_{2}^{*}(p) \leq F_{1}^{*}(p)$, for all $p \in[\underline{p}, \bar{p}]$. 
That is, firm 2's strategy first-order stochastically dominates firm 1's strategy. [See Figure 4]. This is an intuitive result because it indicates that the lower-SCR share generator submits high prices with a greater probability than the higherSCR share generator. This probability tends to be higher when the degree of asymmetry, $\left(\theta_{1}-\theta_{2}\right)$, exhibits higher values. When $\pi=\frac{1}{2}$ and $\eta_{\theta_{1}}>0$, the probability that $p_{2}>p_{1}$ is reduced to:

$$
\left.\operatorname{Pr} \equiv \operatorname{Prob}\left(p_{2}>p_{1}\right)\right|_{\pi=0.5}=\left.\left[1-\frac{1}{2} \frac{\eta_{\theta_{1}}}{\eta_{\theta_{2}}}\right]\right|_{\pi=0.5}=\frac{1}{2}\left(3-\frac{1}{2-3 \theta_{2}}\right),
$$

so that, $\partial[\operatorname{Pr}] / \partial \theta_{2}<0$, and hence, a larger degree of asymmetry between $\theta_{1}$ and $\theta_{2}$ gives the lower-SCR share generator a bigger chance of being the firm which submits higher offer prices.

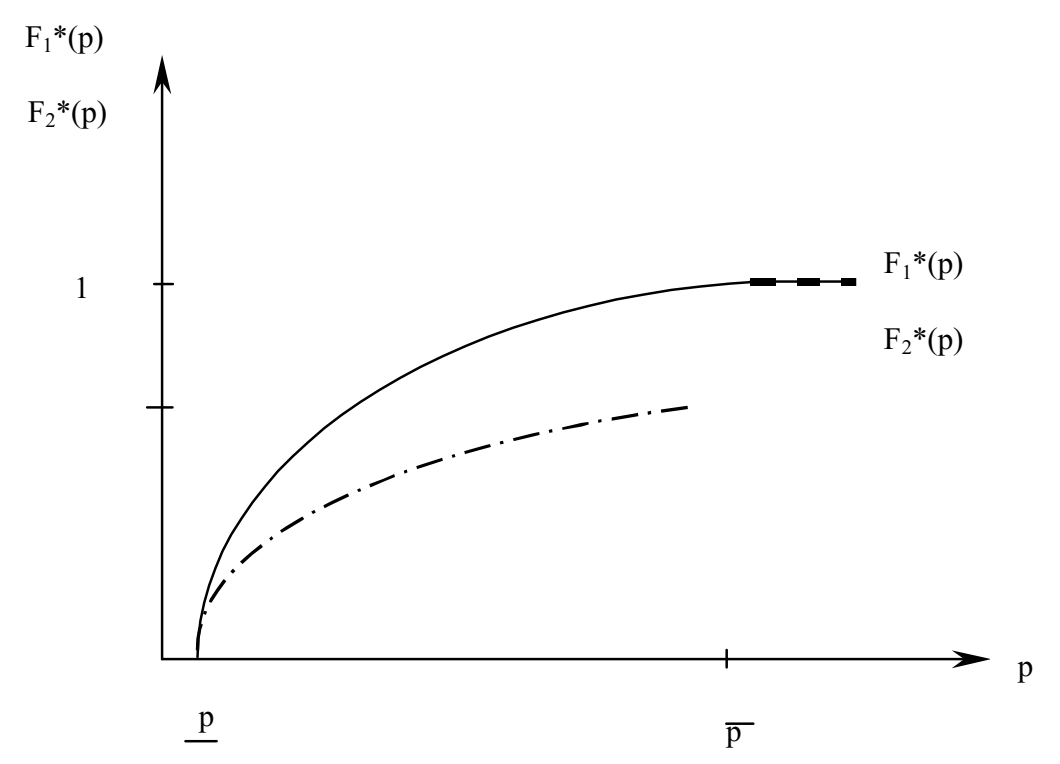

Figure 4: Asymmetric equilibrium strategies. This figure plots the pricing equilibrium strategies in a pool market with asymmetric payments of stranded costs. $\mathrm{F}_{1} *(\mathrm{p})$ and $\mathrm{F}_{2}{ }^{*}(\mathrm{p})$ represent the equilibrium pricing strategies of firm 1 and firm 2, respectively. 
- Case II: $\boldsymbol{\eta}\left(\theta_{1}\right)=\mathbf{0}$

I turn now to the case in which $\eta\left(\theta_{1}\right)=0$, so that, the higher-SCR share generator presents a null incentive to variate marginally its offer price, provided it is the marginal operating unit. What firm 1 earns via generation when its offer price raises is exactly offset by with what it losses in stranded-cost payments, whatever $p_{1} \in\left[p_{r}, \bar{p}\right]$. Since $\eta\left(\theta_{2}\right)$ is strictly bigger than zero, when generator 2 is the marginal operator, it has always an incentive to increase its offer price. Pure-strategy equilibrium is found which is characterized in the proposition below.

Proposition 10 If $0<\pi<1$ and $\eta\left(\theta_{1}\right)=0$, all pure strategy equilibria are given by the offer price pairs $\left(p_{1}, p_{2}\right)$ such that $p_{r} \leq p_{1} \leq v$ and $p_{2}=\bar{p}$.

Proof. Since $\Pi_{2}^{\prime}\left(p_{2}\right)>0$, for all $p_{2}<0$, irrespective of $p_{1}$, then I have that firm 2 always bids at or above marginal cost. Suppose that in equilibrium $p_{1}>p_{2} \geq 0$. Since $\eta\left(\theta_{2}\right)>0$, then I have that $\Pi_{2}^{\prime}\left(p_{2}\right)>0$. Hence, $p_{1}>p_{2} \geq 0$ cannot be an equilibrium. Likewise, $p_{1}=p_{2} \geq 0$ cannot be an equilibrium either since any firm can increase its profits when it undercuts $p_{1}$ to $p_{1}-\varepsilon$ ( $\varepsilon$ sufficiently small) in an amount equal to $\frac{\pi}{2}\left(p-2 \eta\left(\theta_{i}\right) \varepsilon\right)>0, i=1,2$. Suppose now that $0=p_{1}=p_{2}$. This cannot be an equilibrium either, since firm 2 can increase its profits by $\varepsilon(1-\pi) \eta\left(\theta_{2}\right)>0$ when raising its offer price by $\varepsilon>0$. Therefore, it cannot happen in equilibrium that $p_{2} \leq p_{1}$.

I can then prove that any offer-price pairs $\left(p_{1}, p_{2}\right)$ such that $p_{r} \leq p_{1} \leq v$ and $p_{2}=\bar{p}$ constitute a Nash equilibrium. Suppose that $p_{2}>p_{1}$. Hence $\left.\Pi_{2}\left(p_{2}\right)\right|_{p_{2}>p_{1}}$ is strictly increasing in its argument and it attains a maximum at $\bar{p}$. If $p_{2}=\bar{p}$, firm 
1's expected marginal profits are given by:

$$
\left.\left[\Pi_{1}^{\prime}\left(p_{1}\right)\right]\right|_{\left(p_{2}=\bar{p}\right)}=\left\{\begin{array}{lll}
0 & \text { for all } & p_{1} \in\left[p_{r}, \bar{p}\right] \\
\pi & \text { for all } p_{1}<p_{r},
\end{array}\right.
$$

so that, the low-bidding generator is indifferent between any offer price $p_{1} \in$ $\left[p_{r}, \bar{p}\right]$. It is easy to check that playing $p_{2}=\bar{p}$ generates higher expected payoffs to firm 2 than undercutting firm 1's bid when

$$
p_{1}<v=\left(\frac{1-\pi}{2-\pi}\right) \bar{p}
$$

which implies that firm 2 has no incentive to deviate from $\bar{p}$ whenever $p_{1} \leq$ $v$. Therefore, there exists pure-strategy equilibria, $\left(p_{1}, p_{2}\right)$, in all of which $p_{2}=$ $\bar{p}$ and $p_{r} \leq p_{1} \leq v$. Q.E.D.

From previous proposition I know that the low-SCR share generator bids always at the highest admissible price, $\bar{p}$, so that, it determines the system marginal price when demand is 2 . The generator with high-SCR share is always the lowbidding firm, so that, it determines the system marginal price when demand is 1 , and it is indifferent between any offer price lower than that of its rival. Nevertheless, to ensure that generator with the lower SCR-share does not deviate, it has to bid low enough so that the low-SCR share generator's profit will be less when undercutting than profits that it would obtain bidding at the highest admissible price. Thus, $v$ represents the upper bound for the high-SCR share generator.

I can note that the upper bound on the low-bidding firm's offer price is a decreasing function of the probability of low-demand periods, $\pi$. As $\pi$ increases 
the upper bound on the low-bidding firm's offer price decreases. The intuition for the result is straightforward. Since the incentive to undercut is stronger when the probability of low demand increases, the low-bidding firm must decrease the expected earnings that high-bidding firm could get by undercutting and this happens diminishing its offer price, $p_{1}$. In the limit when $\pi$ is equal to 1 , low-bidding firm's offer price is zero. It is easy to prove that

$$
\lim _{\pi \rightarrow 1} v=0
$$

Firm 1 never bids below $p_{r}$. Since stranded-cost recovery payments are always constant at the maximum level $\bar{S}$ for any price below $p_{r}$, a marginal increase in the system marginal price only affects firm 1's expected profits through generation payments. This implies that firm 1 has always an incentive to raise its offer price, for all $p_{1}<p_{r}$, in order to increase its expected generation revenues at no cost in terms of expected stranded payments.

- Case III: $\boldsymbol{\eta}\left(\theta_{1}\right)<\mathbf{0}$

In this case I assume that the firms present opposite pricing incentives when they are the marginal operating unit. When generator 1 sets the system marginal price, its expected profits are decreasing with its own bid; whereas generator 2's marginal expected profits are increasing in its offer price. There exists a purestrategy equilibrium in this game characterized by Proposition (11) below.

Proposition 11 If $0<\pi<1$ and $\eta\left(\theta_{1}\right)<0$, then there exists a pure-strategy equilibrium in which player 2 plays $\bar{p}$ and player 1 plays $p_{r}$. 
Proof. Since I know that firm 2 bids always at or above marginal cost, then, firm 1's marginal benefits are given by

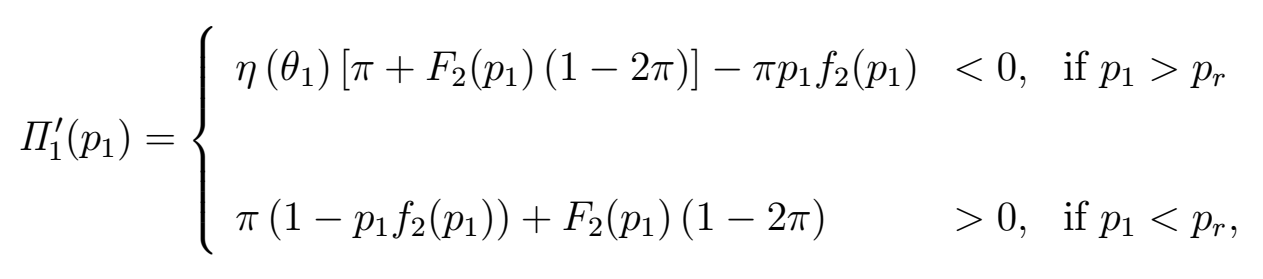

so that, player 1 achieves its maximum expected payoffs at $p_{r}$. Since $\eta\left(\theta_{2}\right)$ is strictly positive and firm 1 bids at $p_{r}$, I have that firm 2's expected profits are increasing in its own offer price, so that, profit maximization requires firm 2 to bid at the highest admissible price, $\bar{p}$. Q.E.D.

Since $\eta\left(\theta_{1}\right)<0$ firm 1 has always an incentive to reduce its price when it has a positive probability of being the marginal operator. Likewise, firm 2 has an incentive to increase its bid when it sets the system marginal price. Because $0<\pi<1$ both generators have always a positive probability of setting the system marginal price, irrespective of their bids. Therefore I have that generator 1 achieves its maximum expected profits at $p_{r}$, the price which maximizes the expected SCR payoffs; whereas generator 2 maximizes its expected revenues bidding at $\bar{p}$, the price which maximizes the expected generation payoffs. Consequently, the offer-price pair $\left(p_{r}, \bar{p}\right)$ constitutes the unique pure-strategy equilibrium of this game.

\subsection{Alternative SCR Payment Rules}

Von der Fehr and Harbord (1993), using a similar auction-model than mine, demonstrated that price competition in a deregulated wholesale market for electricity without stranded-cost repayments is likely to create distortions in the gener- 
ators' pricing incentives, which lead to prices above marginal costs. ${ }^{19}$ In previous sections I proved that SCR repayments based on expected demand (ex ante) can serve to partially mitigate these practices. I even found particular cases in which SCR repayments led the generator with higher proportion of SCR payoffs to bid below marginal cost.

In this section I analyze a different SCR payment structure, which is based on actual (ex post) demand. Our goal is to determine whether this regulatory rule leads firms to price at marginal cost. I show that when the firm's shares of SCR repayments are equal to their generating capacity shares, there is a pure-strategy equilibrium where all firms bid at marginal cost.

Under the new payment rule, for a given system marginal price $p$, total SCR payoffs are given by:

$$
S(p)= \begin{cases}S-\left(p-p^{*}\right) & \text { when } \quad d=1 \\ S-2\left(p-p^{*}\right) & \text { when } \quad d=2,\end{cases}
$$

Ex ante, prior to the actual opening of the market, when both independent firms simultaneously submit their offer prices, the SCR payoffs for each firm are given

\footnotetext{
${ }^{19}$ Wolfram (1998a) also finds evidence of positive price costs mark-ups in a study on market power in the England and Wales electricity spot market.
} 
by:

$$
S_{i}\left(p_{i}\right)= \begin{cases}\left\{S-\left[\left(\pi p_{j}+2(1-\pi) p_{i}\right)-p^{*} E[d]\right]\right\} \theta_{i} & \text { if } p_{i}>p_{j}, \\ \left\{S-\left[p_{i}-p^{*}\right] E[d]\right\} \theta_{i} & \text { if } p_{i}=p_{j}, \\ \left\{S-\left[\left(\pi p_{i}+2(1-\pi) p_{j}\right)-p^{*} E[d]\right]\right\} \theta_{i} & \text { if } p_{i}<p_{j}, \\ i, j=1,2, i \neq j \text { and } p_{i} \leq \bar{p} . & \end{cases}
$$

Let $G\left(p \mid p_{i}\right)$ denote the total industry's expected generation revenues when firm $i$ bids at $p_{i}$, and $E\left[p \mid p_{i}, d=D\right]$ be the firm $i$ 's expected system marginal price when firm $i$ bids at $p_{i}$ and demand is equal to $D$. Then, current expected SCR payoffs corresponding to firm $i$ can be written as,

$$
S_{i}\left(p_{i}\right)=\left\{S-\left(G\left(p \mid p_{i}\right)-p^{*} E[d]\right)\right\} \theta_{i},
$$

where

$$
\begin{gathered}
G\left(p \mid p_{i}\right)=\pi E\left[p \mid p_{i}, d=1\right]+2(1-\pi) E\left[p \mid p_{i}, d=2\right] \\
E\left[p \mid p_{i}, d=1\right]=p_{i}\left(1-F_{j}\left(p_{i}\right)\right)+\int_{\underline{p}}^{p_{i}} \rho f_{j}(\rho) d \rho, \\
E\left[p \mid p_{i}, d=2\right]=p_{i} F_{j}\left(p_{i}\right)+\int_{p_{i}}^{\bar{p}} \rho f_{j}(\rho) d \rho
\end{gathered}
$$

and $E[d]=2-\pi$. Firm $i$ 's expected profits are given by

$$
\Pi_{i}\left(p_{i}\right)=G_{i}\left(p_{i}\right)+S_{i}\left(p_{i}\right)
$$

where $G_{i}\left(p_{i}\right)$ is given by equation $(3)$ and $S_{i}\left(p_{i}\right)$ is denoted by equation (64). Consequently, firm $i$ 's expected marginal profits are equal to:

$$
\Pi_{i}^{\prime}\left(p_{i}\right)=\pi\left(1-F_{j}\left(p_{i}\right)\right)\left(1-\theta_{i}\right)+(1-\pi) F_{j}\left(p_{i}\right)\left(1-2 \theta_{i}\right)-\pi p_{i} f_{j}\left(p_{i}\right) .
$$


The intuition behind equation (69) is as follows. The first two terms in the sum represent the net marginal benefit for firm $i$ of raising $p_{i}$ when firm $i$ determines the system marginal price. Firm $i$ is the marginal operating unit with probability $\pi\left(1-F_{j}\left(p_{i}\right)\right)$, when demand is 1 , and the net marginal benefit for firm $i$ of raising $p_{i}$ in this case is $\left(1-\theta_{i}\right)$. Likewise, when demand is 2 , firm $i$ is the marginal operating unit with probability $(1-\pi) F_{j}\left(p_{i}\right)$, and its net marginal benefit in this case is $\left(1-2 \theta_{i}\right)$. The last term in the sum denotes the event that an increase in $p_{i}$ may force firm $i$ out of the merit order. This happens with probability $\pi f_{j}\left(p_{i}\right)$, and it will in turn entail a reduction of $p_{i}$ in generation revenues.

I focus the analysis only for the case in which I have 'Fluctuating demand periods' since in the rest of cases, 'High demand periods' and 'Low demand periods', similar results are obtained to those achieved under the previous SCR policy. I start by presenting the symmetric case and later on I analyze the asymmetric one.

\subsubsection{Symmetric Case}

Set $\theta_{1}=\theta_{2}=1 / 2$, then,

Proposition 12 If $0<\pi<1$, then there exists a unique pure-strategy equilibrium, in which both generators offer to supply at marginal cost.

Proof. Suppose $\left(p_{i}, p_{j}\right)$ constitutes a pure-strategy equilibrium and $p_{i}<p_{j}$. Hence, from equation (69) I have that

$$
0<\Pi_{i}^{\prime}\left(p_{i}\right)= \begin{cases}\frac{\pi}{2} & \text { if } p_{i} \in\left[p_{r}, \bar{p}\right) \\ \pi & \text { if } \quad p_{i}<p_{r},\end{cases}
$$

so firm $i$ has an incentive to raise its offer price $p_{i}$. Therefore, any offer-price pair 
$\left(p_{i}, p_{j}\right)$ with $p_{i}<p_{j}$ cannot constitute a pure-strategy equilibrium. Suppose now that the offer-price pair $\left(p_{i}, p_{j}\right)$, where $p_{i}=p_{j}>0$, is a pure-strategy equilibrium. If firm $i$ reduces its price by $\varepsilon>0$, then it is easy to check that its expected profits raise by $\frac{1}{2} \pi(p-\varepsilon)>0$ for $\varepsilon$ small enough, which implies that $p_{i}=p_{j}>0$ cannot be a pure-strategy equilibrium. Likewise, $p_{i}=p_{j}<0$ cannot be an equilibrium either, since $\Pi_{i}^{\prime}\left(p_{i}\right)>0$, for all $i$ when $p_{i}<0$, irrespective of $p_{j}$. To complete the proof I need to show that the offer-price pair $\left(p_{i}, p_{j}\right)$ with $p_{i}=p_{j}=0$ constitutes a Nash equilibrium. It is easy to check that no firm has an incentive to deviate, since, for all $i$ and $p_{j}=0, \Pi_{i}\left(p_{i}\right)$ is continuously increasing up to 0 and for all $p_{i} \in[0, \bar{p}]$ remains constant at its maximum value of $\Pi_{i}(0)=\left(S+(2-\pi) p^{*}\right) \frac{1}{2}$. In conclusion, there exists an unique pure equilibrium in which firm $i$ and firm $j$ bid at marginal cost. Q.E.D.

The intuition for the result is straightforward. Let me first analyze generators' pricing incentives when demand is 2 . In this case, the net marginal benefit obtained by the marginal operator when it raises its offer price is zero. What a firm earns via generation when the system marginal price raises is exactly offset by what it losses in stranded costs. On the other hand, when demand is 1 there exists a unique equilibrium in which both generators are bidding at marginal cost. Hence, a unique equilibrium outcome exists with both generators offering to supply at marginal cost.

\subsubsection{Asymmetric Case}

In what follows I assume that $\theta_{2}<\theta_{1}$. I show below that no pure-strategy equilibria are achieved in this game. However, I can show that there is a unique equilibrium in mixed strategies for this game characterized by lemmas 4-6 and 
the following proposition,

Proposition 13 There does not exist an equilibrium in pure strategies. I find an unique equilibrium in mixed strategies defined by two distribution functions $\widetilde{F}_{1}(p)$ and $\widetilde{F}_{2}(p)$ representing the equilibrium pricing strategies of firm 1 and firm 2 , respectively, where $p \in\left[p_{\min }, \bar{p}\right]$, and $p_{\min }$ is given by (74).

$$
\begin{aligned}
& \widetilde{F}_{1}(p)= \begin{cases}\ln \left(e(p / \bar{p})^{\left(1-\theta_{2}\right)}\right) & \text { when } \beta_{2}=0 \\
(p / \bar{p})^{\frac{\beta_{2}}{\pi}}\left[1+\frac{\pi\left(1-\theta_{2}\right)}{\beta_{2}}\right]-\frac{\pi\left(1-\theta_{2}\right)}{\beta_{2}} & \text { when } \beta_{2} \neq 0,\end{cases} \\
& \widetilde{F}_{2}(p)= \begin{cases}\left(1-\theta_{1}\right)\left[1-\frac{\bar{p}}{p}\left(\frac{1}{e}\right)^{\frac{1}{\theta_{1}}}\right] & \text { when } p<\bar{p} \text { and } \beta_{2}=0 \\
(p / \bar{p})^{\frac{\beta_{1}}{\pi}\left[\frac{\frac{1}{\beta_{1}} \pi\left(1-\theta_{1}\right)}{\left.\left(\frac{\pi\left(1-\theta_{2}\right)}{(1-\pi)\left(1-2 \theta_{2}\right)}\right)^{\frac{\beta_{1}}{\beta_{2}}}\right]-\frac{\pi\left(1-\theta_{1}\right)}{\beta_{1}}}\right.} \text { when } p<\bar{p} \text { and } \beta_{2} \neq 0,\end{cases} \\
& \widetilde{F}_{2}(\bar{p})=1,
\end{aligned}
$$

$$
\text { where } \beta_{i} \equiv(1-\pi)\left(1-2 \theta_{i}\right)-\pi\left(1-\theta_{i}\right), i=1,2 \text {, and }
$$

$$
0<p_{\min }= \begin{cases}\bar{p}\left(\frac{1}{e}\right)^{\frac{1}{1-\theta_{2}}} & \text { when } \beta_{2}=0 \\ \bar{p}\left[\frac{\pi}{(1-\pi)} \frac{\left(1-\theta_{2}\right)}{\left(1-2 \theta_{2}\right)}\right]^{\frac{1}{\beta_{2}} \pi} & \text { when } \beta_{2} \neq 0 .\end{cases}
$$

Proof. Similar to the proof Proposition 8 and 9.

The same intuitions that were explained in the case I of section 5.1.3 apply here when I compare the results here obtained. There is a unique equilibrium for the full 
game in which each firm set prices according to continuous and strictly increasing distribution functions, $\widetilde{F}_{i}(\bar{p}), i=1,2$, over a connected and identical support, $\left[p_{\min }, \bar{p}\right]$. From equation $(71)$ and $(72)$ it follows that when the probability that both firms will be operating (i.e., $\pi$ is small), more probability mass is placed on higher prices (and vice versa). As in the case I of section 5.1.3 I find the presence of an atom of positive probability in the distribution function of the lower-SCR share generator. Firm 2 names the uppermost price, $\bar{p}$, with positive probability and this mass point at $\bar{p}$, is an increasing function of the degree of asymmetry in the proportion of SCR shares and a decreasing function of $\pi$. Likewise, I have that the lowest price in the support of the players' strategies, $p_{\min }$, is strictly greater than the marginal cost, and that this lowest price is a decreasing function of $\pi$ and an increasing function both of the degree of asymmetry in the SCR shares and the highest admissible price, $\bar{p}$. It can be easily shown that:

$$
\begin{gathered}
\lim _{\pi \rightarrow 0} p_{\min }=\bar{p} \text {, and } \\
\lim _{\pi \rightarrow 1} p_{\min }=0 .
\end{gathered}
$$

From equation (71) and (72), I obtain the following result:

Corollary $4 \widetilde{F}_{2}(p) \leq \widetilde{F}_{1}(p)$, for all $p \in\left[p_{\min }, \bar{p}\right]$.

That is, firm 2's strategy first-order stochastically dominates firm 1's strategy, so that the lower-SCR share generator submits high prices with a greater probability than the higher-SCR share generator. This probability tends to be higher when the degree of asymmetry in SCR shares, $\left(\theta_{1}-\theta_{2}\right)$, is higher. 


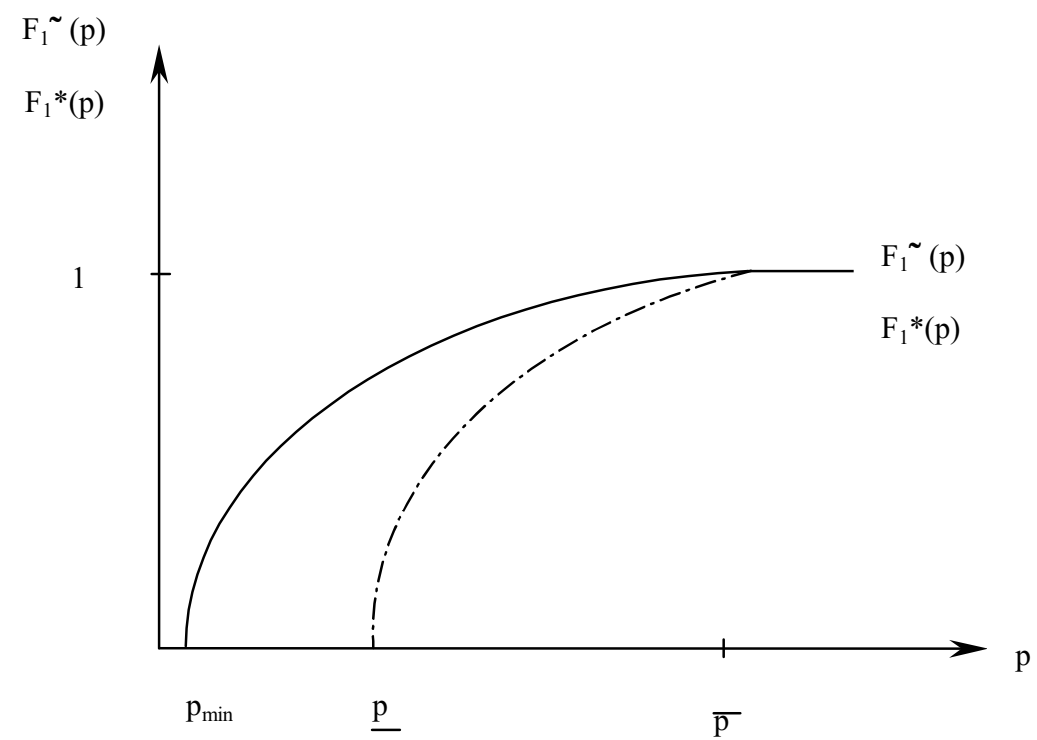

Figure 5: Firm 1's equilibrium strategies under two alternative SCR payment rules. $\mathrm{F}_{1}{ }^{*}(\mathrm{p})$ denotes firm 1's pricing equilibrium strategy in a pool market in which SCR payments are based on expected demand; whereas $\mathrm{F}_{1} \tilde{}(\mathrm{p})$ represents firm 1's pricing equilibrium in an otherwise identical pool market in which SCR payments are based on real demand.

Main differences arise when I compare the results here obtained with those obtained under the previous SCR payment rule. If $\theta_{2}$ and $\pi$ are determined in a such a way that $\eta\left(\theta_{i}\right)>0$ for all $i$, I find that an SCR payment rule based on real demand makes price competition fiercer than an SCR rule in which payments are based on expected demand. In particular I have that:

(a) for $\pi \geq 1 / 2, p_{\min }$ is strictly lower than $\underline{p}$, and

(b) for $\pi \geq 1 / 2$ and for all $p \in\left[p_{\min }, \bar{p}\right], \widetilde{F}_{i}(p) \geq F_{i}^{*}(p), i=1,2$, that is, generators' strategy under the former rule fist-order stochastically dominates the strategy of the generators with the new SCR policy. [See Figure 5 and 6]. 


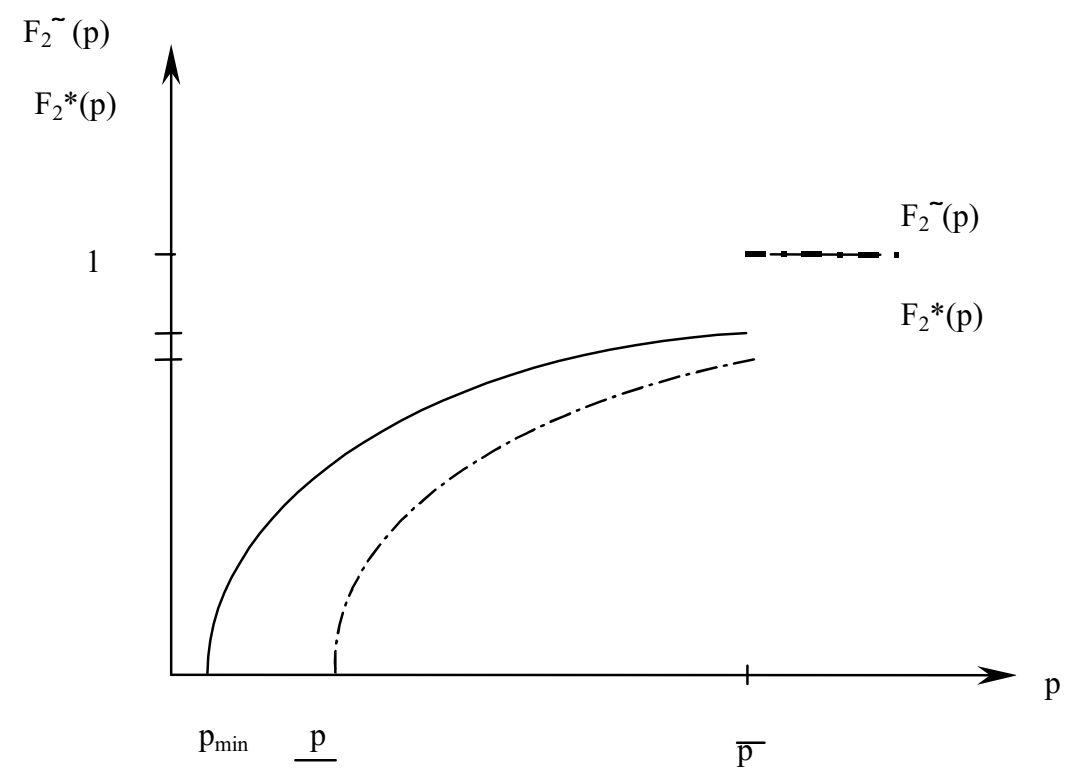

Figure 6: Firm 2's equilibrium strategies under two alternative SCR payment rules. $\mathrm{F}_{2}{ }^{*}(\mathrm{p})$ denotes firm 2's equilibrium strategies in a pool market in which SCR payments are based on expected demand; whereas $\mathrm{F}_{2} \sim$ (p) represents firm 2's pricing equilibrium in an otherwise identical pool market in which SCR payments are based on real demand.

Only in the cases in which $\pi$ and $\theta_{2}$ are lower enough than $1 / 2$ I do not observe this stochastic dominance in all the support of prices. In particular, for $\pi$ and $\theta_{2}$ lower enough than $1 / 2$ I find that $p_{\min }$ is higher than $\underline{p}$, so that, $\widetilde{F}_{i}(p)<F_{i}^{*}(p)$, $i=1,2$, for all $p \in\left[p_{\min }, v\right)$ with $v<\bar{p}$, and $\widetilde{F}_{i}(p)>F_{i}^{*}(p), i=1,2$, for all $p \in(v, \bar{p}]$. It implies that

(c) the atom of positive probability that the lower-SCR share generator has at $\bar{p}$ is always lower under the new payment rule.

On the other hand, if $\theta_{2}$ and $\pi$ are determined in a such a way that $\eta\left(\theta_{1}\right)<0$, I know from Proposition 11 that under an SCR payment rule based on expected demand, a perfect equilibrium exists in which the lower SCR share generator 
always bid at $\bar{p}$ and the higher SCR share generator bids at $p_{r}$, so that, the lower SCR share generator charges lower prices under the alternative payment rule than in the former one; the opposite happens with the higher SCR share generator.

Therefore, I conclude that the enactment of an SCR payment rule based on real demand encourages price competition, so that, it serves to alleviate the above marginal-cost pricing distortion typically found in spot markets competition. I observe that price competition in a spot market in which SCR payments are based on real demand is, in general, fiercer than price competition in an otherwise identical market in which the SCR set up is based on expected demand. In particular, for the symmetric case, I am able to show that marginal-cost pricing constitutes an equilibrium for all range of demand distributions.

\section{Concluding Remarks}

In this paper I have developed a model which analyzes price competition in the deregulated Spanish electricity market. I have shown that stranded-cost recovery and efficient competition are not necessarily in conflict. The model clarifies the overall competitive effect of the recovery of stranded costs under the existing institutional set-up. Whether equilibrium prices are higher or lower than marginal cost depends both on the distribution of total stranded-cost payments among industry participants and on the exact rules used to define these entitlements. This paper also establishes the conditions under which I should expect cost shifting practices to be avoided. The main purpose of the paper has been to address the issue of stranded-cost recovery in a formal model specifically designed to reflect the main institutional features of the new electricity market in Spain. 


\section{References}

[1] Bolle, F. (1992), 'Supply Function Equilibria and the Danger of Tacit Collusion: The Case of Spot Markets for Electricity', Energy Economics, April, pp. 94-102.

[2] Green, R. J. (1996), 'Increasing Competition in the British Electricity Spot Market', Journal of Industrial Economics, vol. 44, no. 2, pp. 205-16.

[3] Green, R. J. and D. M. Newbery (1992), 'Competition in the British Electricity Spot Market', Journal of Political Economy, vol. 100, no. 5, pp. 929-53.

[4] Joskow, P. L. (1996), 'Does Stranded Cost Recovery Distort Competition?', The Electricity Journal, April, pp. 31-45.

[5] Kahn, E. (1994), 'Can Regulation and Competition Coexist? Solutions to the Stranded Cost Problem and Other Conundra', The Electricity Journal, October, pp. 23-35.

[6] Kühn, K.-U, and B. Jullien (1998), 'Price Caps and Price Floors: Entry Liberalization and the Stranded Asset Issue', Mimeo, CEMFI.

[7] Kühn, K.-U, and P. Regibeau (1998), ¿¿Ha Llegado la Competencia?: Un Análisis Económico de la Reforma de la Regulación del Sector Eléctrico en España', Informes del Institut d'Anàlisi Econòmica, CSIC.

[8] Klemperer, P. D. and M. A. Meyer (1989), 'Supply Function Equilibria in Oligopoly Under Uncertainty', Econometrica, vol. 57, no. 6, pp. 1243-77.

[9] Lasheras, M. A. (1998), 'Stranded Costs in the Spanish Electricity Industry', Working Paper 006/98, CNSE. 
[10] Marín. P., and A. García-Díaz (2000), 'Strategic Bidding in Electricity Pools with Short-Lived Bids: An Application to the Spanish Market', CEPR Discussion Paper No. 2567, U. Carlos III, Madrid.

[11] Newbery, D. M. (1998), 'Competition, Contracts, and Entry in the Electricity Spot Market', RAND Journal of Economics, vol. 29, no. 4, pp. 727-49.

[12] Ocaña, C. and A. Romero (1998), 'A Simulation of the Spanish Pool', CNSE working paper.

[13] Von der Fehr, N.-H., and D. Harbord (1992), 'Spot Market Competition in the UK Electricity Industry', Memorandum no. 9/1992, Department of Economics, University of Oslo.

[14] Von der Fehr, N.-H., and D. Harbord (1993), 'Spot Market Competition in the UK Electricity Industry', The Economic Journal 103, pp. 531-546.

[15] Von der Fehr, N.-H., and D. Harbord (1997a), 'Capacity Investment and Competition in Decentralized Electricity Markets', Mimeo, Department of Economics, University of Oslo.

[16] Von der Fehr, N.-H., and D. Harbord (1997b), 'Competition in Electricity Spot Markets', Mimeo, Department of Economics, University of Oslo.

[17] Wolak, F. A. and R. H. Patrick (1997), 'The Impact of Market Rules and Market Structures on the Price Determination Process in the England and Wales Electricity Market', CEPR Discussion Paper No. 463, Department of Economics, Stanford University. 
[18] Wolfram, C. D. (1998a), 'Measuring Duopoly Power in the British Electricity Spot Market', Mimeo, Department of Economics, Harvard University.

[19] Wolfram, C. D. (1998b), 'Strategic Bidding in a Multiunit Auction: An Empirical Analysis of Bids to Supply Electricity in England and Wales', RAND Journal of Economics, vol. 29, no. 4, pp. 703-25. 